\title{
Specific effects of large asteroids on the orbits of terrestrial planets and the ASETEP database ${ }^{\star}$
}

\author{
S. Aljbaae and J. Souchay
}

\author{
Observatoire de Paris, SYRTE/CNRS UMR8630, 61 avenue de l'Observatoire, 75014 Paris, France \\ e-mail: [safwan.aljbaae; jean.souchay]@obspm.fr
}

Received 2 December 2011 / Accepted 16 January 2012

\section{ABSTRACT}

\begin{abstract}
The necessity to take into account the perturbations caused by a large number of asteroids on the terrestrial planets is fundamental in the construction of modern numerical ephemeris on the solar system. Therefore about 300 of the largest asteroids were taken into account in recent ephemeris. Yet, the uncertainty on the mass values of the great majority of these asteroids constitutes a crucial and the main limit of accuracy of this ephemeris. Consequently, it is important to conduct a specific and detailed study of their individual effects especially on the terrestrial planets, which are far more affected than the giant planets. This was already done explicitly, but only for Mars and for only two orbital elements $(a$ and $\lambda)$. We aim both to confirm these previous results and to extend the study to all orbital elements and to the other three terrestrial planets (Mercury, Venus and the Earth), which are priori less affected by asteroid perturbations. Our methodology consists in several steps: we carried out precise computations of the orbital motions of the planets at short $(100 \mathrm{y})$ and longer $(1000 \mathrm{y})$ time scales with numerical integration. For that purpose we included the eight planets and also considered 43 of the most powerful asteroids. These were added to the numerical integrations once separately and once combined to determine their specific effects on the orbital elements of the Earth and the three other terrestrial planets. This procedure also allowed us to assess the spatial geocentric coordinates of the three terrestrial planets. We determined the signal that represents the effects by simple subtraction. Then we systematically analyzed this signal by FFT (fast Fourier transform), and finally we adjusted the signal with a set of sinusoidal components. We analyzed in detail the variations of the six orbital elements $a, e, i, \Omega, \tilde{\omega}$ and $\lambda$ of Mercury, Venus, the Earth-Moon barycenter (EMB) and Mars that are caused by the individual influences of the set of our 43 selected asteroids. We compared our results for Mars with the analytical ones on the semi-major axis and the longitude. The tow studies agree very well. All our results, consisting of 1032 different curves (43 asteroids $\times 4$ planets $\times 6$ orbital elements) and the related tables that provide the fitted Fourier and Poisson components are gathered the ASETEP database (asteroid effect on the terrestrial planets). Moreover, we include in this database the influence of our sample of 43 asteroids on three fundamental parameters: the distance and the bidimensional orientation vector $(\alpha, \delta)$ from the EMB to each of the other terrestrial planets. This database, which will be regularly updated by taking into account more asteroids with improved mass determinations, constitutes a precious tool for understanding specifically the influence of the large asteroids on the orbital motion of the terrestrial planets, and also for better understanding how modern ephemeris can be improved.
\end{abstract}

Key words. gravitation - minor planets, asteroids: general - ephemerides - astronomical databases: miscellaneous - astrometry celestial mechanics

\section{Introduction}

There are two main ways of computing the ephemeris of celestial bodies. One is semi-analytical, which was used for the VSOP87 theory of the planets by Bretagnon et al (1987) and the ELP2000 solution for the orbital motion of the Moon (Chapront et al. 1988). In these successful and complex works, the coordinates of the moving bodies are given in the form of Fourier series of fundamental arguments as the mean longitudes of the planets or the Delaunay arguments. The interest of these analytical theories is that they enable us to understand the origin of the countless sinusoidal terms that originate in the perturbing function. But these theories can no longer reach the necessary accuracy to match numerical determinations of the motions that constitute the second way of computation.

Indeed, today the stability and rapidity of the numerical integrators allow an accurate construction of the ephemeris of the solar system's main bodies. As explained by Standish (2004), the accuracy of an ephemeris depends on three major factors. The first one is related to the equations of motion. These equations

\footnotetext{
* Appendices A-C are available in electronic form at http://www. aanda.org
}

might be imperfect for instance because they do not take all the gravitational effects into account or because the underlying analytical model contains some errors. The second factor concerns the integration of motion, which inevitably contains uncertainties that have to be estimated. The last factor is the exact determination of basic parameters such as the initial conditions (positions, velocities, masses etc.), which are given by the observations, and therefore contain errors that are conditioning the results of the integration. The two first factors are generally believed to be satisfactory, because the equations of motion look correct and complete, whereas the errors accompanying the integration algorithms have been proved to be negligible. The third factor is still subject to various investigations and numerous recent developments, in particular those coming from the recent missions to Mars (Standish 2004; Fienga et al. 2009). The JPL ephemeris are undoubtedly used the most worldwide. Since the construction of an initial release DE200 in 1979, a lot of other versions have been constructed, such as DE405 in 1997, and DE409 in 2003. This last version in particular uses very recent VLBI observations of the MGS (Mars Global Surveyor) in 2001-2003 and Odyssey in 2002-2003, which leads to an accuracy for the determination of the position of Mars at the level 
of a few milliarcseconds. The comparisons between the various versions of JPL ephemerides give a clear insight into the improvements. DE405 for instance, showed an improvement of an order of magnitude over DE200, especially for the inner planets, as explained by Standish (2004).

To evaluate the accuracy limits in the ephemeris of the four inner planets, Standish et al. (2002) considered the presentday knowledge of the asteroid masses determined by various methods, and modeled the distributions of those masses. Then they carried out a Monte-Carlo study, repeatedly adjusting the ephemeris to fit the observational data, by a suitable set of asteroid masses. the authors' conclusion is that by combining accumulated data for more than two decades, the orbits become distorted both in right ascension and in declination by as much as $5 \mathrm{~km}$ or more. At the level of present-time ephemerides accuracy, the influence of asteroids can no longes be neglected, as in the case of DE409. Many asteroids have enough mass to produce a significant gravitational effect on the inner planets. Nevertheless, because of the large uncertainty in the determination of asteroid masses, it is difficult or impossible to evaluate their effect with sufficient accuracy. Yet no specific study of the influence of each asteroid has been conducted to date. A pioneering work was carried out by Williams (1984), giving a list of the most influential asteroids on the orbit of Mars over a short period of time, roughly 50 years. Recently, Mouret et al. (2009) identified and provided a list of the main perturbers of Mars, which could cause significant disturbances over the next 50 years as well. Their analytical analysis is based on a harmonic decomposition of the perturbations on Mars as a function of the mean longitudes of the planet and the asteroid, to the first order in asteroid mass. Still, these two last studies (Williams 1984; Mouret et al. 2009) can be considered as incomplete because they concentrate mainly on two orbital elements, the semi-major axis and longitude of Mars. Moreover, they only focus on this planet.

We aim to carry out an extensive study of the subject in the present paper. In Sect. 2, after determining the asteroidal mass and its accuracy, we select a set of 43 asteroids. We explain in detail in Sect. 3 the theoretical framework and our methodology with which we calculated the perturbing effect of any specific asteroid on a terrestrial planet. In Sect. 4, we determine the effects of our 43 selected asteroids on the six Mars orbital elements, while the effects on the other telluric planets, the Earth (replaced in the following by the EMB (Earth-Moon barycenter), Mercury and Venus are presented in Sect. 5. Thus we reconstruct the asteroidal perturbation as a combination of Fourier and Poisson components for each perturbing asteroid as well as each terrestrial planet and each orbital parameter. Moreover, as an important by-product of these computations, we calculate in Sect. 6 the influences of each asteroid on two fundamental astrometric parameters namely the distance from the EMB to the barycenter of the other terrestrial planets (Mercury, Venus and Mars) and their two-dimensional positioning $(\alpha, \delta)$ in the celestial sphere. Finally we describe in Sect. 7 how we constructed our ASETEP (asteroidal effects on the terrestrial planets) database, which enables one to determine the influence of each asteroid on any of the four terrestrial planets precisely and in detail through their orbital elements and their geocentric positioning.

\section{Mass determinations of the asteroids}

Much information about the size, shape and pole direction of the leading asteroids has been obtained from analyses of light curves at different epochs, occultation, and/or images obtained through adaptive optics and speckle techniques. The mass is one of the important characteristics, necessary for describing the perturbations on other bodies. There are two methods of estimating the mass: one is dynamical, the other is astrophysical.

The dynamical method is based on the analysis of perturbations of the studied asteroid on other celestial bodies. After a pioneering work by Williams (1984), studying how asteroid masses can be determined from their perturbations on Mars, Standish et al. (1989) showed that the measurements of Mars orbit perturbations can be conducted to estimate the masses of Ceres, Pallas and Vesta, with the intermediary of a least-squares adjustment of all ephemeris parameters, including the relevant asteroid masses. This adjustment was compiled on the basis of observational data encompassing the highly accurate Viking Lander ranging data. The accuracy of mass determination through this method highly depends on the precision of positional observations used and on the number of the observations and their distribution.

The astrophysical method is based on the data about the asteroid size and the taxonomic classification. This method assumes that the body has a spherical shape, a homogeneous structure, is single, etc. This method, in contrast to the dynamical one, has the advantage that it can be applied to many objects even if there is no close encounter with other bodies (Kochetova 2004), but is generally marred by a large uncertainty.

\subsection{The mass of Ceres, Pallas and Vesta}

The masses of the three largest asteroids, Ceres, Pallas and Vesta obtained by Standish et al. (1989) starting from the perturbations on Mars orbital motion were $(5.0 \pm 0.2) \times 10^{-10} M_{\mathrm{S}}$, $(1.4 \pm 0.2) \times 10^{-10} M_{\mathrm{S}}$ and $(1.5 \pm 0.3) \times 10^{-10} M_{\mathrm{S}}$ respectively. They were updated by more recent studies, as we will show below. Hilton (1999) explained why the mass determination of Ceres is completely dependent on that of Pallas. The reason is the degeneracy between the two masses, which is in turn caused by the similarity of the semi-major axes of the two asteroids. In consequence, their mean motion is nearly the same, and their mutual synodic period is very long, around $2000 \mathrm{yr}$ (Williams 1989). This amplifies the propagation of the errors on the mass of Pallas to the mass of Ceres, when the mass of the first asteroid is obtained starting from a series of close encounters with the second one. This explains why the mass estimations are highly dependent on old data with poor accuracy. Because of the high Pallas inclination and its high eccentricity, its close encounters with main-belt asteroids occur only rarly, and when they occur, the relative velocity is high so that mass determination is not very efficient. For Vesta, the mass was obtained starting from perturbations of both Ceres and 197 Arete. The values obtained by Hilton (1999) were $M_{\text {Ceres }}=$ $4.39( \pm 0.04) \times 10^{-10} M_{\mathrm{S}}, M_{\text {Pallas }}=1.59( \pm 0.05) \times 10^{-10} M_{\mathrm{S}}$ and $\left.M_{\text {Vesta }}=1.69( \pm 0.11)\right) \times 10^{-10} M_{\mathrm{S}}$. Many new constraints for the masses of the three asteroids were obtained during one decade. For our computations, we have chosen the recent values determined by Pitjeva (2009) from data of the Martian landers and spacecraft by fitting the planet ephemeris to observations. Their values are significantly different from the estimations above, i.e. $4.712( \pm 0.006) \times 10^{-10} M_{\mathrm{S}}$ for Ceres, $1.027( \pm 0.007) \times 10^{-10} M_{\mathrm{S}}$ for Pallas, and $1.344( \pm 0.003) \times 10^{-10} M_{\mathrm{S}}$ for Vesta.

\subsection{The mass of the other large asteroids}

We limit our study to the perturbations produced by asteroids with relatively large and well-constrained masses. According to Mouret et al. (2009), we can rely on 36 asteroid masses derived 
from direct measurements with a precision better than 10 per cent, while only 54 reach the 50 per cent mark. These statistics come from Mouret et al. (2007), Baer et al. (2008a) and Baer database ${ }^{1}$. All these masses were deduced from the gravitational pull exerted by the corresponding asteroid on other solar system objects, mainly smaller asteroids, and in special cases Mars or a spacecraft. In Table 1 we present the set of the 43 asteroids selected in this paper for which we will calculate the gravitational effects on the four terrestrial planets in the following, together with their mass determination and the relative uncertainty. Our choice was guided by two criteria: the asteroid must be big enough and its mass determination satisfactorily accurate. The data were taken from 12 different sources: Pitjeva et al. (2009), Fienga et al. (2009), Baer et al. (2008a), Baer et al. (2008b), Bange (1998), Marchis et al. (2008a), Marchis et al. (2008b), Kochetova (2004), Ivantsov (2008), Aslan et al. (2007), and Yeomans et al. (1997). Notice that in the near future, Gaia may significantly increase the number of favorable encounters to be analyzed for mass determination, as explained by Mouret et al. (2009).

\section{Analytical expression of planet perturbations caused by an asteroid}

After reviewing the classical theory of perturbations for a system of $N$ planets orbiting the Sun, we show in this section how the individual effects of a given asteroid on one of these planets are determined analytically and explain our methodology of characterizing these effects with numerical integration.

\subsection{Theoretical principles}

Consider $N$ planets $P_{1}, \ldots, P_{N}$ orbiting around the Sun $P_{0}$, with mass $m_{0}$, according to Newton's law. The heliocentric position vector $\boldsymbol{r}_{i}$ of a given planet in the frame of this $N+1$ body problem is subject to the second order differential equation:

$$
\frac{\mathrm{d}^{2} \boldsymbol{r}_{i}}{\mathrm{~d} t^{2}}=\operatorname{grad}_{\mathrm{r}_{i}}\left(\frac{G\left(m_{0}+m_{i}\right)}{r_{i}}+R_{i}\right)
$$

where $i=1,2, \ldots, N$ and the parameters $m_{i}$ and $G$ are the mass of the $i$ th. planet and the gravitational constant. $R_{i}$, usually called the disturbing function on the planet $P_{i}$, is written as follows:

$$
R_{i}=\sum_{j \neq i} G m_{j}\left(\frac{1}{\left|\boldsymbol{r}_{i}-\boldsymbol{r}_{j}\right|}-\frac{\boldsymbol{r}_{i} \cdot \boldsymbol{r}_{j}}{r_{j}^{3}}\right) .
$$

This disturbing function causes a perturbation of the planet's osculating orbital elements; in principle each of these perturbations can be calculated analytically according to the classical Lagrange equations for the osculating elements $a, e, i, \Omega, \varpi$ and $\lambda$ (see for instance Murray \& Dermott 1999) (for simplicity we did not take into account the index $i$ in $R_{i}$ )

$$
\begin{aligned}
& \frac{\mathrm{d} a}{\mathrm{~d} t}=\frac{2}{n a} \frac{\partial R}{\partial \lambda} \\
& \frac{\mathrm{d} e}{\mathrm{~d} t}=-\frac{\sqrt{1-e^{2}}}{n a^{2} e}\left(1-\sqrt{1-e^{2}}\right) \frac{\partial R}{\partial \lambda}-\frac{\sqrt{1-e^{2}}}{n a^{2} e} \frac{\partial R}{\partial \varpi}
\end{aligned}
$$

${ }_{1}$ URL: http://home. earthlink.net/ jimbaer1/astmass .htm

$$
\begin{aligned}
\frac{\mathrm{d} \lambda}{\mathrm{d} t} & =n-\frac{2}{n a} \frac{\partial R}{\partial a}+\frac{\sqrt{1-e^{2}}\left(1-\sqrt{1-e^{2}}\right)}{n a^{2} e} \frac{\partial R}{\partial e}+\frac{\tan \frac{1}{2} I}{n a^{2} \sqrt{1-e^{2}}} \frac{\partial R}{\partial I} \\
\frac{\mathrm{d} \Omega}{\mathrm{d} t} & =\frac{1}{n a^{2} \sqrt{1-e^{2}} \sin I} \frac{\partial R}{\partial I} \\
\frac{\mathrm{d} \varpi}{\mathrm{d} t} & =\frac{\sqrt{1-e^{2}}}{n a^{2} e} \frac{\partial R}{\partial e}+\frac{\tan \frac{1}{2} I}{n a^{2} \sqrt{1-e^{2}}} \frac{\partial R}{\partial I} \\
\frac{\mathrm{d} I}{\mathrm{~d} t} & =\frac{-\tan \frac{1}{2} I}{n a^{2} \sqrt{1-e^{2}}}\left(\frac{\partial R}{\partial \lambda}+\frac{\partial R}{\partial \varpi}\right)-\frac{1}{n a^{2} \sqrt{1-e^{2}} \sin I} \frac{\partial R}{\partial \Omega}
\end{aligned}
$$

We focus on the perturbation caused on a planet $P$ (one of the $P_{i}$ ) by an asteroid $P^{\prime}$ of mass $m^{\prime}$ added to the $N+1$ body system considered above. Let the position vector of the new body be denoted by $\boldsymbol{r}^{\prime}$. Generally we define the perturbation $\Delta X$ of one orbital element $X$ of the planet induced by the asteroid as the difference $\Delta X=\widetilde{X}-X$, where $\widetilde{X}$ stands for the perturbed element in the frame of the $N+2$ body problem (with the asteroid) and $X$ for perturbed element in the frame of the $N+1$ body problem (without the asteroid). On an equivalent manner, the perturbing function $\Delta R$ can be written as

$\Delta R=\widetilde{R}-R=G m^{\prime}\left(\frac{1}{\left|\boldsymbol{r}-\boldsymbol{r}^{\prime}\right|}-\frac{\boldsymbol{r} \cdot \boldsymbol{r}^{\prime}}{r^{\prime 3}}\right)$.

We can write the derivative of the perturbation induced by the extra body $P^{\prime}$ on the elements of the planet in the following form (Kuchynka 2010):

$$
\begin{aligned}
\frac{\mathrm{d} \Delta a}{\mathrm{~d} t}= & \frac{2}{n a} \frac{\partial \Delta R}{\partial \lambda} \\
\frac{\mathrm{d} \Delta e}{\mathrm{~d} t}= & -\frac{\sqrt{1-e^{2}}}{n a^{2} e}\left(1-\sqrt{1-e^{2}}\right) \frac{\partial \Delta R}{\partial \lambda}-\frac{\sqrt{1-e^{2}}}{n a^{2} e} \frac{\partial \Delta R}{\partial \varpi} \\
\frac{d \Delta \lambda}{d t}= & \Delta n-\frac{2}{n a} \frac{\partial \Delta R}{\partial a}+\frac{\sqrt{1-e^{2}}\left(1-\sqrt{1-e^{2}}\right)}{n a^{2} e} \frac{\partial \Delta R}{\partial e} \\
\frac{\mathrm{d} \Delta \Omega}{\mathrm{d} t}= & \frac{\tan \frac{1}{2} I}{n a^{2} \sqrt{1-e^{2}}} \frac{1}{n a^{2} \sqrt{1-e^{2}} \sin I} \frac{\partial \Delta R}{\partial I} \\
\frac{\mathrm{d} \Delta \varpi}{\mathrm{d} t}= & \frac{\sqrt{1-e^{2}}}{n a^{2} e} \frac{\partial \Delta R}{\partial e}+\frac{\tan \frac{1}{2} I}{n a^{2} \sqrt{1-e^{2}}} \frac{\partial \Delta R}{\partial I} \\
\frac{\mathrm{d} \Delta I}{\mathrm{~d} t}= & \frac{-\tan \frac{1}{2} I}{n a^{2} \sqrt{1-e^{2}}}\left(\frac{\partial \Delta R}{\partial \lambda}+\frac{\partial R}{\partial \varpi}\right)-\frac{1}{n a^{2} \sqrt{1-e^{2}} \sin I} \frac{\partial \Delta R}{\partial \Omega}
\end{aligned}
$$

The development of the perturbing function as a function of eccentricities and inclinations enables one to obtain the expressions of the perturbations as a function of the orbital elements both of the perturbed body (here the planet) and the perturbing body (the studied asteroid). This development was continued up to the fourth order by Brouwer \& Clemence (1961). To develop the disturbing function $\Delta R$ given in Eq. (4), we distinguished between its direct part $R_{\mathrm{D}}$ and its indirect part $R_{\mathrm{E}}$. According to classical celestial mechanics (see for instance Laskar et al. 1995; or Murray \& Dermott 1999) we have:

$\Delta R=\frac{G m^{\prime}}{a^{\prime}}\left(R_{\mathrm{D}}+\alpha R_{\mathrm{E}}\right)$, 
With $\alpha=\frac{a^{\prime}}{a}$, where $a^{\prime}$ stands for the semi-major axis of the asteroid, and:

$$
\begin{aligned}
& R_{\mathrm{D}}=\frac{a^{\prime}}{\left|\boldsymbol{r}-\boldsymbol{r}^{\prime}\right|} \\
& +\left(C_{1}^{j}+\left(e^{2}+e^{\prime 2}\right) C_{2}^{j}+\left(s^{2}+s^{\prime 2}\right) C_{3}^{j}\right) \cos \left[j \lambda-j \lambda^{\prime}\right] \\
& +e e^{\prime} C_{4}^{j} \cos \left[j \lambda^{\prime}-j \lambda+\varpi^{\prime}-\varpi\right] \\
& +s s^{\prime} C_{6}^{j} \cos \left[j \lambda^{\prime}-j \lambda+\Omega^{\prime}-\Omega\right] \\
& +e C_{7}^{j} \cos \left[j \lambda^{\prime}+(1-j) \lambda-\varpi\right] \\
& +e^{\prime} C_{8}^{j} \cos \left[j \lambda^{\prime}+(1-j) \lambda-\varpi^{\prime}\right] \\
& +e^{2} C_{9}^{j} \cos \left[j \lambda^{\prime}+(2-j) \lambda-2 \varpi\right] \\
& +e e^{\prime} C_{1} 0^{j} \cos \left[j \lambda^{\prime}+(2-j) \lambda-\varpi^{\prime}-\varpi\right] \\
& +e^{\prime} C_{1} 1^{j} \cos \left[j \lambda^{\prime}+(2-j) \lambda-2 \varpi^{\prime}\right] \\
& +e^{\prime} C_{1} 2^{j} \cos \left[j \lambda^{\prime}+(2-j) \lambda-2 \Omega\right] \\
& +s s^{\prime} C_{1} 3^{j} \cos \left[j \lambda^{\prime}+(2-j) \lambda-\Omega^{\prime}-\Omega\right] \\
& +s^{\prime 2} C_{1} 4^{j} \cos \left[j \lambda^{\prime}+(2-j) \lambda-2 \Omega^{\prime}\right] \\
& R_{\mathrm{E}}=-\frac{a^{\prime 2}}{a} \frac{\boldsymbol{r} \cdot \boldsymbol{r}^{\prime}}{r^{\prime 3}}=-\frac{r}{a}\left(\frac{a^{\prime}}{r^{\prime}}\right)^{2} \cos \psi \\
& =-\left(-1+\frac{1}{2} e^{2}+\frac{1}{2} e^{\prime 2}+s^{2}+s^{\prime 2}\right) \cos \left(\lambda^{\prime}-\lambda\right) \\
& -e e^{\prime} \cos \left(2 \lambda^{\prime}-2 \lambda-\varpi^{\prime}+\varpi\right)-\frac{1}{2} e \cos \left(\lambda^{\prime}-2 \lambda+\varpi\right) \\
& -2 s s^{\prime} \cos \left(\lambda^{\prime}-\lambda-\Omega^{\prime}+\Omega\right)+\frac{3}{2} e \cos \left(\lambda^{\prime}-\varpi\right) \\
& -2 e^{\prime} \cos \left(2 \lambda^{\prime}-\lambda-\varpi^{\prime}\right)-\frac{3}{8} e^{2} \cos \left(\lambda^{\prime}-3 \lambda+2 \varpi\right) \\
& -\frac{1}{8} e^{2} \cos \left(\lambda^{\prime}+\lambda-2 \varpi\right)+3 e e^{\prime} \cos \left(2 \lambda-\varpi^{\prime}-\varpi\right) \\
& -\frac{1}{8} e^{\prime 2} \cos \left(\lambda^{\prime}+\lambda-2 \varpi^{\prime}\right)-s^{\prime 2} \cos \left(\lambda^{\prime}+\lambda-2 \Omega^{\prime}\right) \\
& -s^{2} \cos \left(\lambda^{\prime}+\lambda-2 \Omega\right)+2 s s^{\prime} \cos \left(\lambda^{\prime}+\lambda-\Omega^{\prime}-\Omega\right) \\
& -\frac{27}{8} e^{\prime 2} \cos \left(3 \lambda^{\prime}-\lambda-2 \varpi^{\prime}\right) \text {, }
\end{aligned}
$$

\begin{tabular}{|c|c|c|c|c|}
\hline & Name & $M\left[M_{\odot}\right]$ & $\overline{\Delta M[\%]}$ & Authors \\
\hline 1 & Ceres & $0.472 \times 10^{-09}$ & 0.127 & Pitjeva et al. (2009) \\
\hline 2 & Pallas & $0.103 \times 10^{-09}$ & 0.682 & Pitjeva et al. (2009) \\
\hline 3 & Juno & $0.750 \times 10^{-11}$ & 20.000 & Fienga et al. (2009) \\
\hline 4 & Vesta & $0.134 \times 10^{-09}$ & 0.223 & Pitjeva et al. (2009) \\
\hline 6 & Hebe & $0.759 \times 10^{-11}$ & 18.709 & Baer et al. (2008a) \\
\hline 7 & Iris & $0.500 \times 10^{-11}$ & 8.621 & Fienga et al. (2009) \\
\hline 8 & Flora & $0.426 \times 10^{-11}$ & 10.563 & Baer et al. (2008b) \\
\hline 9 & Metis & $0.103 \times 10^{-10}$ & 23.301 & Baer et al. (2008a) \\
\hline 10 & Hygiea & $0.454 \times 10^{-10}$ & 3.304 & Baer et al. (2008a) \\
\hline 11 & Parthenope & $0.316 \times 10^{-11}$ & 1.899 & Baer et al. (2008a) \\
\hline 13 & Egeria & $0.820 \times 10^{-11}$ & 19.512 & Baer et al. (2008b) \\
\hline 14 & Irene & $0.413 \times 10^{-11}$ & 17.676 & Baer et al. (2008b) \\
\hline 15 & Eunomia & $0.168 \times 10^{-10}$ & 4.762 & Baer et al. (2008a) \\
\hline 16 & Psyche & $0.129 \times 10^{-10}$ & 13.178 & Baer et al. (2008a) \\
\hline 17 & Thetis & $0.617 \times 10^{-12}$ & 10.373 & Baer et al. (2008a) \\
\hline 18 & Melpomene & $0.151 \times 10^{-11}$ & 33.775 & Baer et al. \\
\hline 19 & Fortuna & $0.541 \times 10^{-11}$ & 14.048 & Baer et al. (2008a) \\
\hline 20 & Massalia & $0.242 \times 10^{-11}$ & 16.942 & Bange (1998) \\
\hline 21 & Lutetia & $0.129 \times 10^{-11}$ & 9.302 & Baer et al. (2008b) \\
\hline 22 & Kalliope & $0.407 \times 10^{-11}$ & 2.457 & Marchis et al. (2008b) \\
\hline 24 & Themis & $0.567 \times 10^{-11}$ & 37.919 & Baer et al. (2008b) \\
\hline 28 & Bellona & $0.700 \times 10^{-11}$ & 28.571 & \\
\hline 29 & Amphitrite & $0.100 \times 10^{-10}$ & 35.000 & Baer et \\
\hline 31 & Euphrosyne & $0.313 \times 10^{-}$ & 18.850 & \\
\hline 45 & Eugenia & $0.900 \times 10^{-11}$ & 33.333 & Ivantso \\
\hline 46 & Hestia & $0.109 \times 10^{-10}$ & 62.385 & \\
\hline 47 & $\mathrm{Agl}$ & $0^{-11}$ & 39.450 & \\
\hline 48 & Dor & $0^{-11}$ & 49.180 & \\
\hline 49 & Pal & $0^{-11}$ & 18. & \\
\hline 52 & Eur & $0^{-11}$ & 22. & \\
\hline 65 & $\mathrm{Cyb}$ & $0^{-11}$ & 23.979 & \\
\hline 87 & Sylv & $0^{-11}$ & 0.404 & \\
\hline 88 & This & $0^{-11}$ & 29.196 & \\
\hline 90 & Antiope & $0.414 \times 10^{-12}$ & 1.208 & Baer et al. (2008a) \\
\hline 107 & Camilla & $0.563 \times 10^{-11}$ & 2.664 & Marchis et al. (2008b) \\
\hline 111 & Ate & $0.840 \times 10^{-10}$ & 22.619 & Ivantsov (2008) \\
\hline 121 & Hermione & $0.272 \times 10^{-11}$ & 5.515 & Marchis et al. (2005) \\
\hline 130 & Elektra & $0.332 \times 10^{-11}$ & 6.024 & Marchis et al. (2008a) \\
\hline 165 & Loreley & $0.160 \times 10^{-10}$ & 62.500 & Aslan et al. (2007) \\
\hline 189 & Phthia & $0.187 \times 10^{-13}$ & 34.225 & Baer et al. (2008a) \\
\hline 243 & Ida & $0.192 \times 10^{-13}$ & 4.688 & Baer et al. (2008a) \\
\hline 253 & Mathilde & $0.519 \times 10^{-13}$ & 4.239 & Yeomans et al. (1997) \\
\hline 283 & Emma & $0.694 \times 10^{-12}$ & 2.162 & Marchis et al. (2008a) \\
\hline
\end{tabular}

where $e^{\prime}, \lambda^{\prime}, \varpi^{\prime}, \Omega^{\prime}$ stand for the orbital elements of the asteroid. $\psi$ is the angle between the position vectors $\boldsymbol{r}$ and $\boldsymbol{r}^{\prime}, s=\sin \frac{1}{2} i$ $s^{\prime}=\sin \frac{1}{2} i^{\prime}$. The coefficients $C_{i}^{j}$ depend on the Laplace coefficients

$b_{s}^{j}(\alpha)=\frac{1}{\pi} \int_{0}^{2 \pi} \frac{\cos j \rho \mathrm{d} \rho}{\left(1-2 \alpha \cos \rho+\alpha^{2}\right)^{s}}$.

The developments in (7) and (8) show that after integration of the variational Eqs. (5) we can expect that the variations of orbital elements be expressed as a series of linear combinations of $\lambda$ and $\lambda^{\prime}$, taking into account that the parameters $\tilde{\omega}, \tilde{\omega}^{\prime}, \tilde{\Omega}$ and $\tilde{\Omega}^{\prime}$ have a very low frequency with respect both to $\lambda$ and $\lambda^{\prime}$. Therefore, they can be considered as nearly constant during the interval of time considered (100 y or $1000 \mathrm{y}$ ). This explains why both Williams (1984) and Mouret et al. (2009) constructed their developments of $a_{\text {Mars }}$ and $\lambda_{\text {Mars }}$ only with the help of sinusoidal terms with high frequency, function of the arguments of the form $j \lambda+j^{\prime} \lambda^{\prime}$. Nevertheless this study is incomplete, because it does not take into account two long-periodic terms that can come from two different origins: first the resonant terms in (7) and (8) with very
Table 1. Mass estimation of the 43 asteroids selected in this paper, with their relative uncertainty.

low frequency; and second the long periodic terms in the disturbing function with arguments as a linear combination of the sole $\tilde{\omega}, \tilde{\omega}^{\prime}, \tilde{\Omega}$ and $\tilde{\Omega}^{\prime}$ not shown in (7) and (8).

The planetary orbital perturbations due to the asteroids were also discussed by Williams (1984) and Simon (1987), focusing exclusively on the planet Mars. Simon (1987) describes the analytical construction of programs to calculate the first and second derivatives of the Lagrange equations, and to express the theoretical perturbations due to an asteroid on the six ecliptical elements of a planet $\Delta \sigma_{k}$, where the variables $\sigma_{k=1, \ldots, 6}$ are: $a, \lambda$, the mean longitude (written as $\lambda=\lambda_{0}+n t, n$ being the mean motion), $k=e \cos \varpi, h=e \sin \varpi, q=\sin \frac{i}{2} \cos \Omega, p=\sin \frac{i}{2} \sin \Omega$. The method is based on a harmonic decomposition with respect to the mean longitudes of the planet $\bar{\lambda}$ and the asteroid $\overline{\lambda^{\prime}}$. Finally the perturbations can be written as

$\Delta \sigma_{k}=\sigma_{k}^{s e c} t+\sum_{i, j} a_{i j}^{k} \cos \left(i \bar{\lambda}+j \overline{\lambda^{\prime}}\right)+b_{i j}^{k} \sin \left(i \bar{\lambda}+j \overline{\lambda^{\prime}}\right)$ 
as an extension of this work, Mouret et al. (2009) presented in a detailed manner the application of this decomposition for each perturbation of some selected asteroids on the Mars semi-major axis and longitude which were also the only two orbital elements studied by Williams (1984).

\subsection{Methodology of studying asteroidal effects}

For the studies mentioned above, the corresponding analytical developments of the perturbing function $\Delta R$ expressed in (6)(8) from the orbital elements of the two bodies considered (the planet and the perturbing asteroid) are particularly cumbersome and complex, all the more so if we aim to include very longperiodic components, which are difficult to determine analytically, and could be treated as polynomial expansions. But it is possible to evaluate the perturbations in a straightforward manner from numerical integration. Therefore we computed the classical nine-body problem (the Sun and the eight planets), and then carried out the same integration with the sole addition of the perturbing asteroid (Ceres, Pallas, etc.). A simple substraction of the two corresponding signals of one orbital parameter of the planet gives a clear and direct determination of the effect of the asteroid on this parameter.

As mentioned above, the objective of this work is to try to assess the specific influence of ecah of the 43 big selected asteroids on the motion of the terrestrial planets. For that goal we focused our efforts in the following complementary steps:

- we evaluated and then removed the quadratic variation of the differential signal, to isolate the periodic components;

- we performed the frequency analysis of the signal, using fast Fourier transform to determine the leading frequencies;

- we carried out a nonlinear regression in which the differential signal is modeled by the least-square method following an expression combining Fourier-type and Poisson-type components in the form

$F(t)=\sum_{i=1}^{N} F_{i}(t)=\sum_{i=1}^{N} A_{i} \sin f_{i} t+B_{i} \cos f_{i} t+C_{i} t \sin f_{i} t+D_{i} t \cos f_{i} t$

We evaluated the individual influence of the gravitational action of each asteroid listed in Table 1 on the six orbital elements of each of the four terrestrial planets. Because of the number of asteroids considered (43), of orbital elements (6) and of the terrestrial planets (4), we obtained atotal of $43 \times 6 \times 4=1032$ curves, which are gathered together with the related tables of components $A_{i}, B_{i}, C_{i}, D_{i}$ in a database called ASETEP (asteroid effects on the terrestrial planets), as detailed in Sect. 7. In addition, we also calculated and included in this data base the influences of each asteroid on the distance from the EMB to a given terrestrial planet (Mercury, Venus or Mars) and its orientation vector with respect to the EMB. This is of particular interest for the specific study of geocentric observations of the planets.

Because of the very huge number of results above, our purpose in the next section is only to present a few characteristic examples, and some generalizing tables, which aim to understand both the quality of our determinations and the impact of the gravitational effects of each asteroid on the orbital parameters of the terrestrial planets. Although these effects are included in the construction of modern ephemeris of planets, the individual signature of each asteroid is generally not explicitly given, and the effect of mass uncertainty is not fully characterized. One

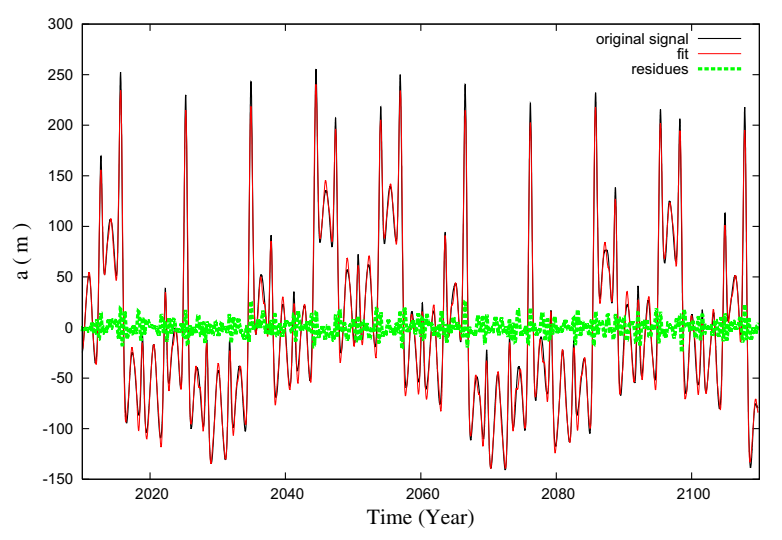

Fig. 1. Effects of Ceres on $a_{\text {Mars }}$ for a $100 \mathrm{y}$ time interval from JJ 2009.81; raw signal (black), fitting curve (red) and residuals (in green).

of the interests of our study is to give complete empirical tables of the asteroidal effects on the orbital elements of a given planet, which could be easily re-adjusted (by simple proportionality) after revision of the asteroial masses. Then we can classify the asteroidal effects by the range of amplitude or/and frequency.

\section{Perturbation on the Mars orbital parameters}

By using the methodology detailed in the previous section, we computed at first the effects of the asteroids on Mars orbital parameters with the help of a Runge-Kutta twelfth order integration, with a 0.01-day stepsize. The rectangular coordinates obtained with respect to the ecliptic and equinox of J2000.0 are directly converted into orbital parameters with respect to this reference plane and point.

\subsection{Perturbation on $a_{\text {Mars }}$ and $\lambda_{\text {Mars }}$}

As a basic and typical example of our computations, and to compare them with other authors, such as Mouret et al. (2009), we show in Figs. 1 and 2 the influence of the gravitational action of Ceres on the Mars semi-major axis and longitude. The time interval here is $1000 \mathrm{y}$ starting from 2009 Sept. 26, i.e. between JD 2009.81 and JD 3009.81. For the clarity we plotted the figures for a $100 \mathrm{y}$ time span. According to (10), we fitted the curves as a sum of Fourier (with coefficients $A_{i}$ and $B_{i}$ ) and Poisson components $\left(C_{i}\right.$ and $\left.D_{i}\right)$.

In both curves, with peak-to-peak amplitudes of $400 \mathrm{~m}$ and 0.006 " for $a_{\text {Mars }}$ and $\lambda_{\text {Mars }}$, respectively, we observe the good quality of the fit resulting from the least-squares-analysis: the fitting curve can hardly be distinguished from the original one. The flat curve represents the residuals obtained after subtracting a combination of 27 sinusoids for the semi-major axis from the original signal, and 10 sinusoids for the longitude. These sinusoids are listed in Tables 2 and 3 in the typical ASETEP database format. Notice that similar tables have been generated automatically for the 1032 cases mentioned above.

$t$ is given in Julian year: its value is $t=2009.81$ at the origin and not $t=0$, so that the value of the Poisson coefficients contribution can be quite high all along the interval of time explored. Nevertheless, this high value is fully compensated by the high value of some Fourier components. In other words, to best fit the signal according to (10) requires introducing two contributions that can be very high individually compared with the signal itself but which give the best fit when mixed together. Therefore 
Table 2. Coefficients of Fourier and Poisson series for the effects of Ceres on $a_{\text {Mars }}$.

\begin{tabular}{|c|c|c|c|c|c|c|c|c|c|}
\hline $\begin{array}{r}\text { Period } \\
\text { (Day) }\end{array}$ & $\begin{array}{l}\text { Period } \\
\text { (Year) }\end{array}$ & $\begin{array}{l}\text { SIN } \\
(\mathrm{m})\end{array}$ & $\begin{array}{r}\mathrm{COS} \\
(\mathrm{m})\end{array}$ & (m) & $\begin{array}{r}T \text { SIN } \\
\times 10^{-4}(\mathrm{~m})\end{array}$ & $\begin{array}{r}T \mathrm{COS} \\
\times 10^{-4}(\mathrm{~m})\end{array}$ & $\times 10^{-3}(\mathrm{~m})$ & $\begin{array}{l}\text { Amplitud } \\
\times 10^{1}(\mathrm{~m})\end{array}$ & Asteroid \\
\hline 27960.94 & 76.55 & 2.644 & 2.158 & 3.413 & 0.291 & -3.054 & 0.432 & 0.563 & 1_Ceres \\
\hline 16191.36 & 44.33 & -54.282 & -53.165 & 75.981 & 67.182 & 62.329 & 8.815 & 5.757 & 1_Ceres \\
\hline 4886.42 & 13.38 & -1.227 & 9.966 & 10.042 & 2.164 & -13.844 & 1.958 & 0.691 & 1_Ceres \\
\hline 3754.72 & 10.28 & 15.277 & 57.810 & 59.794 & -9.105 & -0.557 & 0.079 & 5.954 & 1_Ceres \\
\hline 3047.01 & 8.34 & -16.680 & -0.495 & 16.687 & 7.171 & 0.221 & 0.031 & 1.542 & 1_Ceres \\
\hline 1877.01 & 5.14 & 24.877 & 16.008 & 29.582 & -20.336 & -10.365 & 1.466 & 2.495 & 1_Ceres \\
\hline 1251.31 & 3.43 & 8.691 & -0.233 & 8.694 & -10.205 & 0.628 & 0.089 & 0.671 & 1_Ceres \\
\hline 1161.51 & 3.18 & 6.924 & -12.634 & 14.407 & 6.635 & 2.299 & 0.325 & 1.484 & 1_Ceres \\
\hline 887.06 & 2.43 & 3.562 & -39.634 & 39.793 & 14.293 & 19.194 & 2.714 & 3.622 & 1_Ceres \\
\hline 717.51 & 1.96 & -5.645 & -11.862 & 13.136 & 9.587 & 5.867 & 0.830 & 1.149 & 1_Ceres \\
\hline 687.06 & 1.88 & -3.017 & -0.612 & 3.078 & 1.168 & -1.459 & 0.206 & 0.304 & 1_Ceres \\
\hline 602.38 & 1.65 & -4.163 & -2.346 & 4.779 & 6.308 & 0.588 & 0.083 & 0.316 & 1_Ceres \\
\hline 580.76 & 1.59 & -43.229 & 24.966 & 49.921 & -13.036 & -34.487 & 4.877 & 4.935 & 1_Ceres \\
\hline 502.95 & 1.38 & -11.922 & 15.858 & 19.840 & -7.375 & -15.356 & 2.172 & 1.844 & 1_Ceres \\
\hline 443.53 & 1.21 & -0.836 & 8.157 & 8.199 & -5.500 & -8.805 & 1.245 & 0.669 & 1_Ceres \\
\hline 408.23 & 1.12 & 11.695 & -37.093 & 38.893 & -56.454 & 184.861 & 26.143 & 1.956 & 1_Ceres \\
\hline 396.66 & 1.09 & 1.263 & 2.717 & 2.996 & -3.399 & -2.282 & 0.323 & 0.215 & 1_Ceres \\
\hline 387.17 & 1.06 & 19.798 & 0.132 & 19.798 & -3.570 & 24.294 & 3.436 & 2.008 & 1_Ceres \\
\hline 350.98 & 0.96 & 9.686 & -4.009 & 10.483 & -0.729 & 12.473 & 1.764 & 0.962 & 1_Ceres \\
\hline 320.97 & 0.88 & 3.050 & -3.512 & 4.652 & 0.594 & 5.911 & 0.836 & 0.402 & 1_Ceres \\
\hline 314.71 & 0.86 & 4.284 & 2.959 & 5.207 & -5.783 & 3.139 & 0.444 & 0.473 & 1_Ceres \\
\hline 290.37 & 0.79 & -7.373 & -1.951 & 7.626 & 5.054 & -12.518 & 1.770 & 0.819 & 1_Ceres \\
\hline 272.16 & 0.75 & 13.490 & 11.265 & 17.575 & -66.768 & -54.343 & 7.685 & 0.852 & 1_Ceres \\
\hline
\end{tabular}

Notes. Bias: $0.137559 \times 10^{+2}$; linear: $-0.377681 \times 10^{-2} ; T^{2}: 0.333290 \times 10^{-5}$. The next-to-last column indicates the peak-to-peak amplitude of the total mixed component for the $1000 \mathrm{y}$ time interval considered.

Table 3. Coefficients of Fourier and Poisson series for the effects of Ceres on $\lambda_{\text {Mars }}$.

\begin{tabular}{|c|c|c|c|c|c|c|c|c|c|}
\hline $\begin{array}{r}\text { period } \\
\text { (Day) }\end{array}$ & $\begin{array}{l}\text { period } \\
\text { (Year) }\end{array}$ & $\begin{array}{r}\text { SIN } \\
\times 10^{-5}\left({ }^{\prime \prime}\right) \\
\end{array}$ & $\begin{array}{r}\mathrm{COS} \\
\times 10^{-5}\left({ }^{\prime \prime}\right) \\
\end{array}$ & $\times 10^{-4}\left({ }^{\prime \prime}\right)$ & $\begin{array}{r}T \text { SIN } \\
\times 10^{-8}\left({ }^{\prime \prime}\right) \\
\end{array}$ & $\begin{array}{r}T \mathrm{COS} \\
\times 10^{-8}\left({ }^{\prime \prime}\right) \\
\end{array}$ & $\times 10^{-8}\left({ }^{\prime \prime}\right)$ & $\begin{array}{l}\text { Amplitud } \\
\times 10^{-2}\left({ }^{\prime \prime}\right)\end{array}$ & Asteroid \\
\hline 27961.03 & 76.55 & -10.158 & 13.521 & 1.691 & 0.841 & 0.666 & 0.942 & 0.021 & 1_Ceres \\
\hline 16190.53 & 44.33 & 149.608 & -165.221 & 22.289 & -14.986 & 19.171 & 27.112 & 0.177 & 1_Ceres \\
\hline 15442.23 & 42.28 & -8.026 & -1.417 & 0.815 & 2.600 & 0.650 & 0.919 & 0.001 & 1_Ceres \\
\hline 4886.18 & 13.38 & -11.271 & -0.854 & 1.130 & 1.674 & 0.200 & 0.282 & 0.007 & 1_Ceres \\
\hline 3754.68 & 10.28 & -56.393 & 15.559 & 5.850 & 0.449 & -0.867 & 1.227 & 0.057 & 1_Ceres \\
\hline 3046.73 & 8.34 & -0.633 & -5.797 & 0.583 & -0.101 & 0.045 & 0.064 & 0.006 & 1_Ceres \\
\hline 1877.01 & 5.14 & -7.474 & 12.606 & 1.465 & 0.362 & -1.003 & 1.418 & 0.013 & 1_Ceres \\
\hline 1161.51 & 3.18 & 7.066 & 3.973 & 0.811 & -0.223 & 0.274 & 0.387 & 0.008 & 1_Ceres \\
\hline 887.06 & 2.43 & 11.749 & 1.247 & 1.182 & -0.559 & 0.397 & 0.562 & 0.011 & 1_Ceres \\
\hline 580.76 & 1.59 & -5.492 & -9.687 & 1.114 & 0.781 & -0.210 & 0.297 & 0.011 & 1_Ceres \\
\hline
\end{tabular}

Notes. Bias: 0.221687 ; linear: $-0.550293 \times 10^{-4} ; T^{2}:-0.278178 \times 10^{-7}$. The next-to-last column indicates the peak-to-peak amplitude of the total mixed component for the $1000 \mathrm{y}$ time interval considered.

we should not refer directly to the values of $A_{i}, B_{i}, C_{i}$ and $D_{i}$ to evaluate the amplitude of a component at a given frequency $f_{i}$ in (10) but to the peak-to-peak amplitude of $F_{i}(t)$ during the interval of time considered. This peak-to-peak amplitude is given in the next-to-last columns of Tables 2 and 3, where each component has been ranged in decreasing order of period. For information and to avoid too many data in the paper, the results of the effects of Ceres on $e_{\text {Mars }}, i_{\text {Mars }}, \Omega_{\text {Mars }}$ and $\varpi_{\text {Mars }}$ are given in Figs. A. 1 to A.4 and Tables A.1 to A.4.

For comparison we also show in Figs. 3 and 4 the effects of Pallas and Vesta on the Mars semi-major axis for the same time interval as in Fig. 1. The peak-to-peak amplitudes reach roughly $200 \mathrm{~m}$ and $400 \mathrm{~m}$, this last value is roughly the same as for Ceres, but the nature of the three signals is quite different from each other. For the sake of clarity the tables characterizing the adjustment are presented in Tables A.5 and A.6.

\subsection{Comparison with the analytical results in Mouret et al. (2009)}

It is interesting and challenging to compare our numerical results with the analytical ones found by Mouret et al. (2009) when using developments as in (7) and (8). For that purpose it is necessary to choose the same time interval as these authors, that is to say $1000 \mathrm{y}$, because the developments in series are highly dependent on this time interval. In Tables 4 and 5 we show this comparison for the variation of the Mars semi-major axis and mean longitude due to the gravitational influence of Ceres, Pallas and 


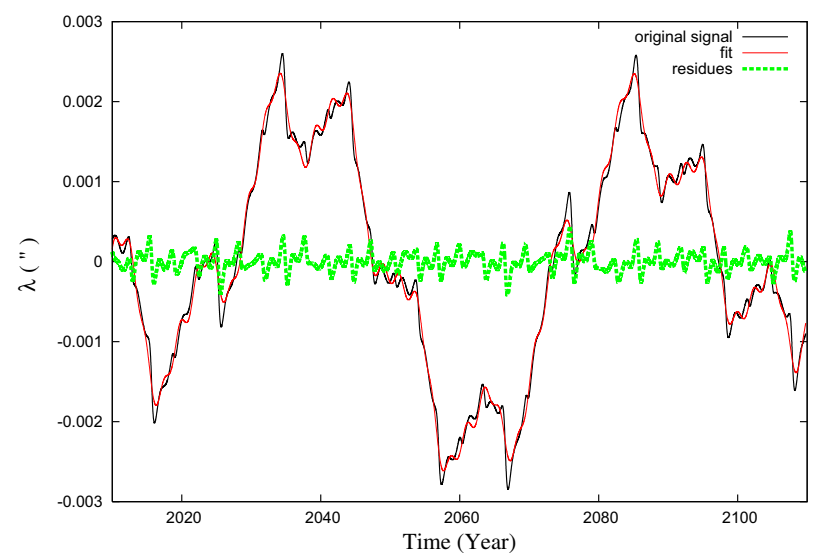

Fig. 2. Effects of Ceres on $\lambda_{\text {Mars }}$ for a $100 \mathrm{y}$ time interval from JJ 2009.81; raw signal (in black), fitting curve (in red) and residuals (in green)

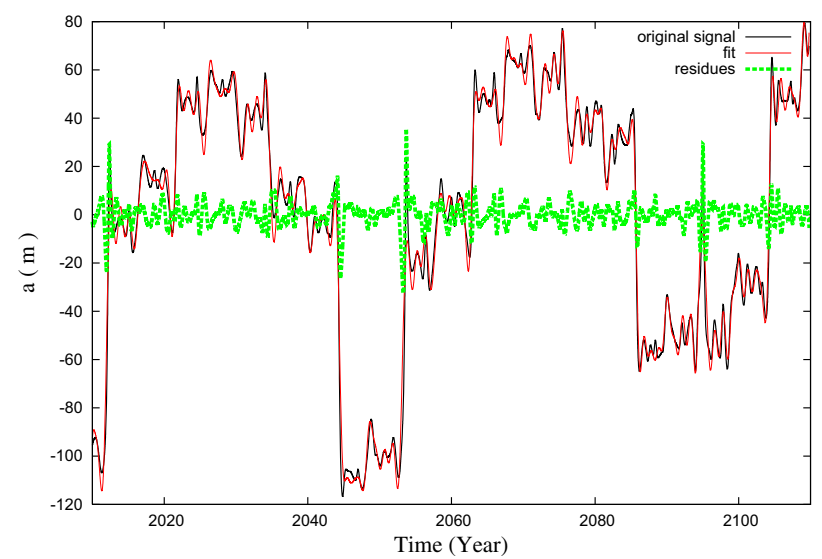

Fig. 3. Effects of Pallas on $a_{\text {Mars }}$ for a $100 \mathrm{y}$ time interval from JJ 2009.81; raw signal (in black), fitting curve (in red) and residuals (in green).

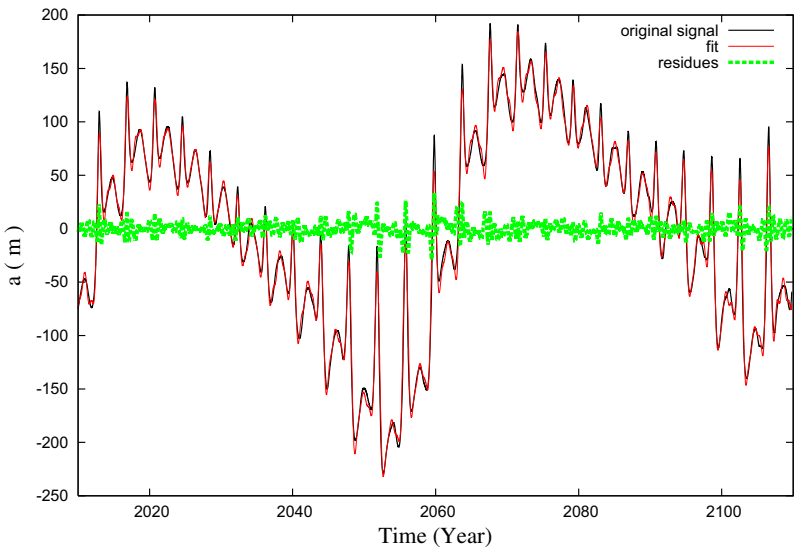

Fig. 4. Effects of Vesta on $a_{\text {Mars }}$ for a $100 \mathrm{y}$ time interval from JJ 2009.81; raw signal (in black), fitting curve (in red) and residuals (in green).

Vesta. We can notice the remarkable general agreement between our numerical determination of the periods and amplitudes of the sinusoidal components that characterize the signal, and the analytical terms developed by Mouret et al. (2009), whose the arguments are a linear combination of the mean longitudes of Mars and the asteroid.
For the effect of Ceres on $a_{\text {Mars }}$ (Table 4) a small but significant discrepancy arises only for the leading term with period $44.33 \mathrm{y}$ and amplitude $57.57 \mathrm{~m}$, which seems to correspond to the component with the period $45.77 \mathrm{y}$ and $60.59 \mathrm{~m}$ amplitude in the above paper. This discrepancy probably arises because we used a quadratic regression and removed it from the signal to isolate the periodic parts, which should affect the determination of low-frequency terms. We also notice components in our calculations that are not mentioned in the paper above, with significant amplitudes $19.56 \mathrm{~m}, 8.52 \mathrm{~m}, 5.63 \mathrm{~m}$ and $4.78 \mathrm{~m}$ and periods $1.12 \mathrm{y}, 0.75 \mathrm{y}, 76.55 \mathrm{y}$ and $0.56 \mathrm{y}$. the reason for this could be that analytical developments, even at a low order of masses and eccentricities, are cumbersome with a mixing of many sinusoidal contributions involving the mean longitudes. Therefore some components may be missing.

For the effect of Ceres on $\lambda_{\text {Mars }}$, the comparison between our results and Mouret et al. (2009) still agrees very well for the majority of components both in amplitudes and periods. Differences similar to those noted for $a_{\text {Mars }}$ concern the leading term with period $44.33 \mathrm{y}$ instead of $45.77 \mathrm{y}$ and amplitude 1.77 mas (milliarcsecond).

The agreement is almost perfect for the influences of Pallas and Vesta, if we excludee large amplitudes without counterparts in the analytical developments, such as the component with amplitude $19.02 \mathrm{~m}$ and period $1.12 \mathrm{y}$ for $a_{\text {Mars }}$ and the secondlargest component with amplitude 0.333 mas and period $59.79 \mathrm{y}$ for $\lambda_{\text {Mars }}$.

\subsection{Perturbations on the other orbital parameters $e, i, \Omega, \tilde{\omega}$}

The gravitational effects of Ceres and other leading asteroids on Mars orbital parameters $e_{\text {Mars }}, i_{\text {Mars }}, \Omega_{\text {Mars }}, \tilde{\omega}_{\text {Mars }}$ have not been explicitly given either by Williams (1984) or by Mouret et al. (2009) although their relative amplitude is of the same order (and sometimes even larger) than the corresponding effects on $a_{\text {Mars }}$ and $\lambda_{\text {Mars }}$ described above.

Two important remarks about the curves plotted for Ceres, Pallas and Vesta in Figs. 5 to 8 need to be made. First of all, in contrast to what happens for the semi-major axes (see Fig. 1), long periodic effects that can be characterized by linear or quadratic expressions appear clearly, in particular for $i_{\text {Mars }}$ (Fig. 5) and $\Omega_{\text {Mars }}$ (Fig. 7), for which they dominate the periodic oscillations, even during the short time span considered here (100 y). Second, we can observe that although its mass is considerably smaller than that of Ceres (with a ratio roughly $1 / 3$ ), the effect of Vesta on the Mars orbital elements can be significantly stronger, as is the case for $e_{\text {Mars }}$ (Fig. 6) and $\tilde{\omega}_{\text {Mars }}$ (Fig. 8). For the three asteroids considered here, the peak-to-peak amplitudes are on the order of $10^{-8}$ for $e_{\text {Mars }}, 1$ mas (milliarcsecond) for $i_{\text {Mars }}, 0 . ' 05$ for $\Omega_{\text {Mars }}$ and $0{ }^{\prime} 01$ for $\tilde{\omega}_{\text {Mars }}$, in the $100 \mathrm{y}$ time interval considered.

In Figs. A.1-A.4 we show the effects of Ceres after the quadratic regression is removed. For each of the parameters, leading sinusoidal signatures appear clearly and the same fitting method as previously can be applied. Results of the decomposition are shown in Tables A.1-A.4.

\subsection{Amplitude of the perturbations for each parameter and each asteroid}

As we already mentioned in Sect. 3.2, we extended our study to the 1032 cases ( 43 asteroids $\times 6$ planets $\times 6$ orbital elements). The output of our computations is presented in Table 6: we 
Table 4. Comparisons of the amplitude of the sinusoids found in this paper with the analytical ones of Mouret et al. (2009) of the effects of Ceres, Pallas and Vesta on $a_{\text {Mars }}$.

\begin{tabular}{|c|c|c|c|c|c|c|}
\hline \multicolumn{2}{|c|}{ Our analysis } & \multicolumn{5}{|c|}{ Mouret et al. (2009) } \\
\hline \multirow[t]{2}{*}{$\begin{array}{r}\text { Period } \\
\text { (y) }\end{array}$} & $\begin{array}{r}\text { Amplitude } \\
(\mathrm{m})\end{array}$ & $\begin{array}{r}\text { Period } \\
\text { (y) }\end{array}$ & $\begin{array}{r}\text { Amplitude } \\
\text { (m) }\end{array}$ & $\begin{array}{r}\mathrm{Ar} \\
i \lambda_{\mathrm{M}} \\
\mathrm{i}\end{array}$ & $\begin{array}{l}\text { gument } \\
+\quad j \lambda_{c}\end{array}$ & jo \\
\hline & & Ceres & & & & \\
\hline 10.280 & 59.5370 & 10.25 & 59.390 & 1 & -2 & \\
\hline 44.330 & 57.5675 & 45.77 & 60.587 & & & \\
\hline 1.590 & 49.3516 & 1.59 & 49.517 & 2 & -2 & -2 \\
\hline 2.429 & 36.2161 & 2.43 & 36.352 & 2 & -3 & -3 \\
\hline 5.139 & 24.9480 & 5.12 & 25.132 & 2 & -4 & 4 \\
\hline 1.118 & 19.5619 & & & & & \\
\hline 1.060 & 20.0837 & 1.06 & 19.897 & 3 & -3 & -3 \\
\hline 1.377 & 18.4410 & 1.38 & 18.550 & 3 & -4 & 4 \\
\hline 8.342 & 15.4159 & 8.37 & 15.708 & 1 & -3 & 3 \\
\hline 3.180 & 14.8437 & 3.18 & 14.900 & 1 & -1 & -1 \\
\hline 1.964 & 11.4949 & 1.96 & 11.369 & 3 & -5 & \\
\hline 0.961 & 9.6248 & 0.96 & 9.694 & 4 & -5 & \\
\hline 0.745 & 8.5178 & & & & & \\
\hline 0.795 & 8.1945 & 0.79 & 7.944 & 4 & -4 & 4 \\
\hline 13.378 & 6.9088 & 13.20 & 7.465 & 3 & -7 & 7 \\
\hline 3.426 & 6.7110 & 3.42 & 6.672 & 3 & -6 & 6 \\
\hline 1.214 & 6.6896 & 1.21 & 6.627 & 4 & -6 & 6 \\
\hline 76.553 & 5.6321 & & & & & \\
\hline 0.738 & 4.8935 & 0.74 & 4.952 & 5 & -6 & 6 \\
\hline 0.862 & 4.7347 & 0.86 & 4.682 & 3 & -2 & \\
\hline 0.559 & 4.7800 & & & & & \\
\hline 0.879 & 4.0163 & 0.88 & 3.934 & 5 & -7 & \\
\hline 1.649 & 3.1624 & 1.65 & 3.665 & 4 & -7 & 7 \\
\hline 0.678 & 3.4828 & 0.68 & 3.366 & 4 & -3 & 3 \\
\hline 1.881 & 3.0392 & 1.88 & 2.992 & 1 & & 0 \\
\hline & & Pallas & & & & \\
\hline 49.058 & 73.5324 & 48.65 & 74.350 & 2 & -5 & \\
\hline 1.118 & 19.0229 & & & & & \\
\hline 12.855 & 14.7998 & 12.89 & 14.750 & 3 & -7 & \\
\hline 24.518 & 14.1215 & 24.32 & 13.883 & 4 & -10 & \\
\hline 5.093 & 13.0090 & 5.10 & 13.224 & 2 & -4 & \\
\hline 2.421 & 9.6624 & 2.42 & 9.619 & 2 & -3 & \\
\hline 17.424 & 6.2069 & 17.54 & 7.121 & 5 & -12 & \\
\hline 1.588 & 7.1841 & 1.59 & 6.537 & 2 & -2 & 2 \\
\hline 10.185 & 6.8003 & 10.19 & 6.508 & 1 & -2 & -2 \\
\hline 8.433 & 6.9895 & 8.43 & 6.358 & 1 & -3 & \\
\hline 3.395 & 5.7901 & 3.40 & 5.789 & 3 & -6 & \\
\hline 7.196 & 5.5975 & 7.18 & 5.505 & 3 & -8 & \\
\hline 1.956 & 4.6407 & 1.96 & 4.638 & 3 & -5 & \\
\hline 5.683 & 4.8822 & 5.69 & 4.593 & 4 & -9 & -9 \\
\hline 27.009 & 4.4647 & 27.44 & 3.964 & 7 & -17 & \\
\hline 4.217 & 3.8491 & 4.21 & 3.934 & 2 & -6 & \\
\hline 1.374 & 3.6767 & 1.37 & 3.590 & 3 & -4 & \\
\hline 16.358 & 2.8954 & 16.22 & 3.366 & 6 & -15 & \\
\hline 2.546 & 2.9761 & 2.55 & 2.857 & 4 & -8 & -8 \\
\hline 2.546 & 2.9761 & 1.64 & 2.423 & 4 & -7 & 7 \\
\hline 1.058 & 2.2976 & & & & & \\
\hline 1.210 & 2.1458 & 1.21 & 2.035 & 4 & -6 & \\
\hline & & Vesta & & & & \\
\hline 25.855 & 38.9394 & 25.93 & 38.746 & 2 & -4 & \\
\hline 1.952 & 30.6734 & 1.95 & 30.368 & 2 & -2 & \\
\hline 4.223 & 25.5473 & 4.22 & 24.983 & 2 & -3 & \\
\hline 1.301 & 15.7973 & 1.30 & 15.708 & 3 & -3 & \\
\hline 2.029 & 13.9884 & 2.03 & 13.254 & 3 & -4 & \\
\hline 3.904 & 11.5442 & 3.90 & 11.325 & 1 & -1 & \\
\hline 4.598 & 10.5150 & 4.59 & 9.829 & 3 & -5 & \\
\hline 17.238 & 9.9542 & 17.29 & 9.140 & 3 & -6 & \\
\hline 0.976 & 8.5505 & 0.98 & 8.198 & 4 & -4 & \\
\hline 1.335 & 8.3356 & 1.33 & 8.078 & 4 & -5 & -5 \\
\hline
\end{tabular}

Notes. Coefficients are ranged in decreasing order of amplitude.
Table 5. Comparisons of the sinusoids found in this paper with those in Mouret et al. (2009) of the effects of Ceres, Pallas and Vesta on $\lambda_{\text {Mars }}$.

\begin{tabular}{|c|c|c|c|c|c|c|}
\hline \multicolumn{2}{|c|}{ Our analysis } & \multicolumn{5}{|c|}{ Mouret et al. (2009) } \\
\hline \multirow{2}{*}{$\begin{array}{r}\text { Period } \\
(\mathrm{y})\end{array}$} & \multirow{2}{*}{$\begin{array}{l}\text { Amplitude } \\
\quad \times 10^{-3} \prime \prime\end{array}$} & \multirow{2}{*}{$\begin{array}{r}\text { Period } \\
\text { (y) }\end{array}$} & \multirow{2}{*}{$\begin{array}{l}\text { Amplitude } \\
\times 10^{-3} \prime\end{array}$} & \multicolumn{3}{|c|}{ Argument } \\
\hline & & & & $\begin{array}{r}\mathrm{i} \lambda_{\mathrm{M}} \\
\mathrm{i}\end{array}$ & + & $\begin{array}{r}\mathrm{j} \lambda_{\mathrm{c}} \\
\mathrm{j}\end{array}$ \\
\hline & & Ceres & & & & \\
\hline 10.280 & 0.573 & 10.25 & 0.571 & 1 & & -2 \\
\hline 44.330 & 1.768 & 45.77 & 1.914 & 2 & & -5 \\
\hline 76.553 & 0.205 & & & & & \\
\hline 1.590 & 0.108 & 1.59 & 0.127 & 2 & & -4 \\
\hline 2.429 & 0.108 & 2.43 & 0.109 & 2 & & -2 \\
\hline 5.139 & 0.126 & 5.12 & 0.108 & 2 & & -3 \\
\hline 8.342 & 0.058 & 8.37 & 0.060 & 1 & & -3 \\
\hline 3.180 & 0.080 & 3.18 & 0.039 & 3 & & -4 \\
\hline 13.378 & 0.069 & 13.20 & 0.025 & 3 & & -6 \\
\hline & & Pallas & & & & \\
\hline 49.058 & 2.521 & 48.65 & 2.537 & 2 & & -5 \\
\hline 59.790 & 0.333 & & & & & \\
\hline 24.517 & 0.209 & 24.32 & 0.227 & 4 & & -10 \\
\hline 12.855 & 0.148 & 12.89 & 0.153 & 3 & & -7 \\
\hline 17.424 & 0.088 & 17.54 & 0.099 & 5 & & -12 \\
\hline & & Vesta & & & & \\
\hline 51.657 & 4.372 & & & & & \\
\hline 25.854 & 0.679 & 25.93 & 0.668 & 2 & & -4 \\
\hline 4.223 & 0.112 & 4.22 & 0.110 & 2 & & -3 \\
\hline 40.162 & 0.107 & & & & & \\
\hline 17.237 & 0.104 & 17.29 & 0.103 & 3 & & -6 \\
\hline 1.118 & 0.096 & & & & & \\
\hline 15.779 & 0.083 & & & & & \\
\hline 1.952 & 0.078 & 1.95 & 0.078 & 2 & & -2 \\
\hline 32.816 & 0.078 & & & & & \\
\hline 2.029 & 0.036 & 2.03 & 0.035 & 3 & & -4 \\
\hline 1.301 & 0.032 & 1.30 & 0.031 & 3 & & -3 \\
\hline
\end{tabular}

Notes. Coefficients are ranged in decreasing order of amplitude.

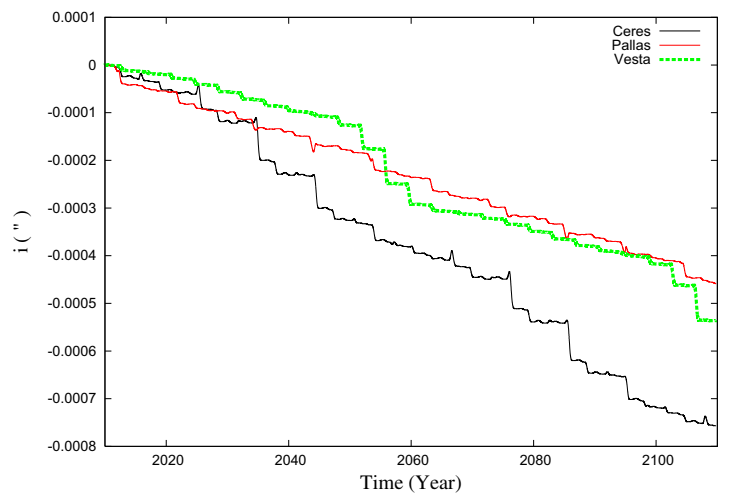

Fig. 5. Effects of Ceres, Pallas and Vesta on $i_{\text {Mars }}$, for a $100 \mathrm{y}$ time interval, starting from JD 2009.81 .

provide the peak-to-peak amplitudes of the effects of each of the 43 asteroids listed in Table 1 on each Mars orbital element. This is done for a $1000 \mathrm{y}$ time interval, beginning in 2009. The amplitudes stand for the total signal including secular trends and periodic components. Moreover, to compare the amplitudes of the effects on $e_{\text {Mars }}$ to those on $a_{\text {Mars }}$ with the same scale, we multiplied these effects by the nominal value $a_{0}$ of the Mars semi-major axis. Thus we can remark that throughout, $a_{0} \times \Delta e$ is significantly higher than $\Delta a$ with a ratio typically on the order of 2 or 3 , but sometimes considerably more, as for Pallas and Vesta. The relatively large amplitude of the effects due to the asteroid 


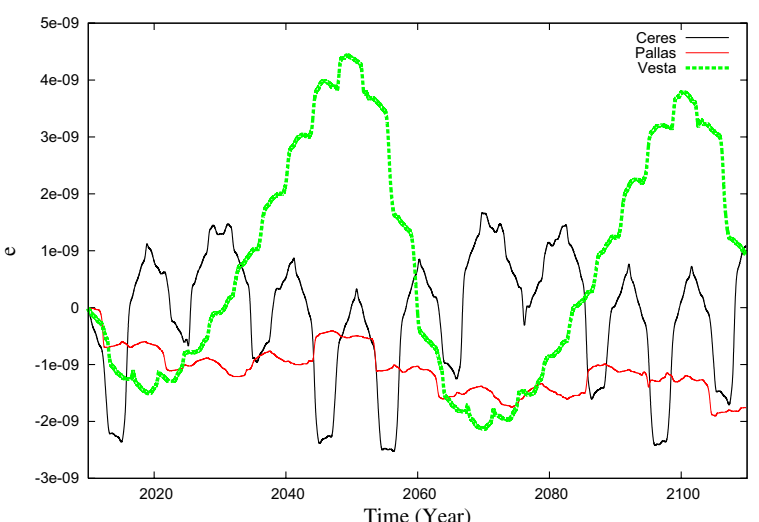

Fig. 6. Effects of Ceres, Pallas and Vesta on $e_{\text {Mars }}$, for a $100 \mathrm{y}$ time interval starting from JD 2009.81.

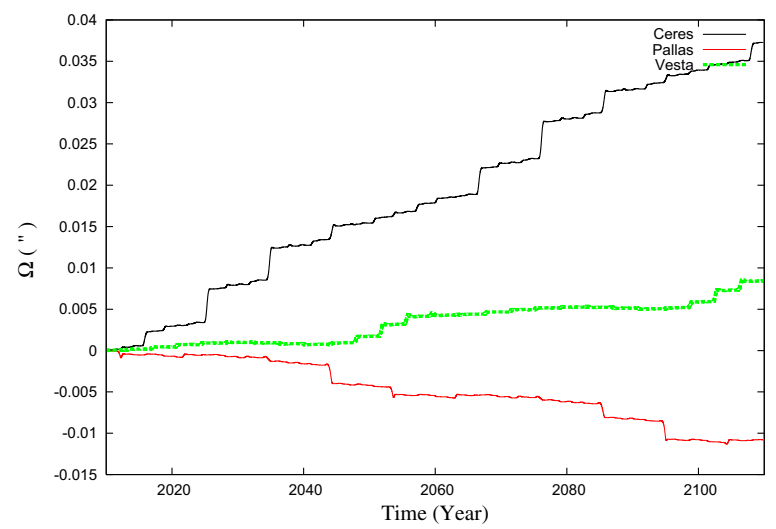

Fig. 7. Effects of Ceres, Palass and Vesta on $\Omega_{\text {Mars }}$, for a $100 \mathrm{y}$ time interval, starting from JD 2009.81.

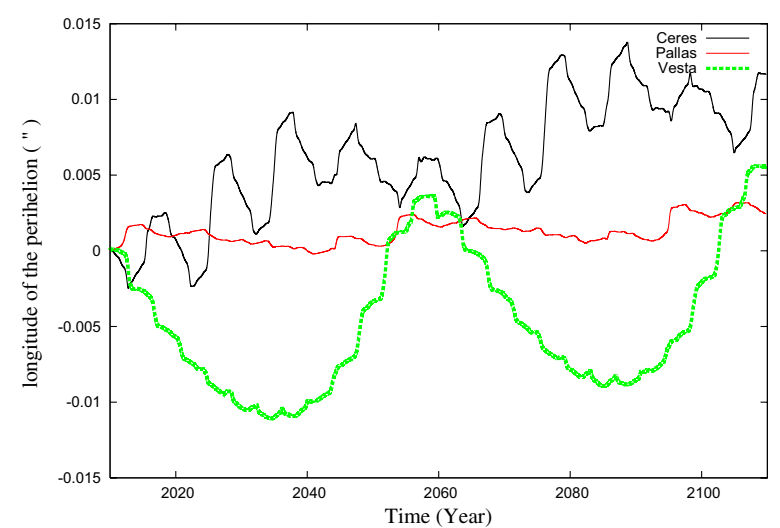

Fig. 8. Effects of Ceres, Pallas and Vesta on $\tilde{\omega}_{\text {Mars }}$, for a $100 \mathrm{y}$ time interval, starting from JD 2009.81.

111 Ate compared to those due to these two last asteroid is remarkable. This is because the mass of Ate is comparable to that of these two big objects. For Ceres, during the $1000 \mathrm{y}$ interval of time considered, the peak-to-peak amplitudes are $416 \mathrm{~m}$ for $\Delta a$, $1300 \mathrm{~m}$ for $a_{0} \times \Delta e, 6.8 \mathrm{mas}$ (millarcsec) for $\Delta i, 0^{\prime} .410$ for $\Delta \Omega$ and 0.197 for $\Delta \lambda$. These effects of the biggest asteroid are surpassed by those of Vesta for $\Delta a(546.7 \mathrm{~m})$ and $a_{0} \times \Delta e(4666 \mathrm{~m})$, by Pallas and 111 Ate for $a_{0} \times \Delta e(2025 \mathrm{~m}$ and $426 \mathrm{~m})$.

As a direct by-product of our results, we present in Table 7 the uncertainty of each Mars orbital parameter due to the mass uncertainty of each selected asteroid. Indeed, according to (6), this uncertainty is directly dependent on the asteroid mass, it is

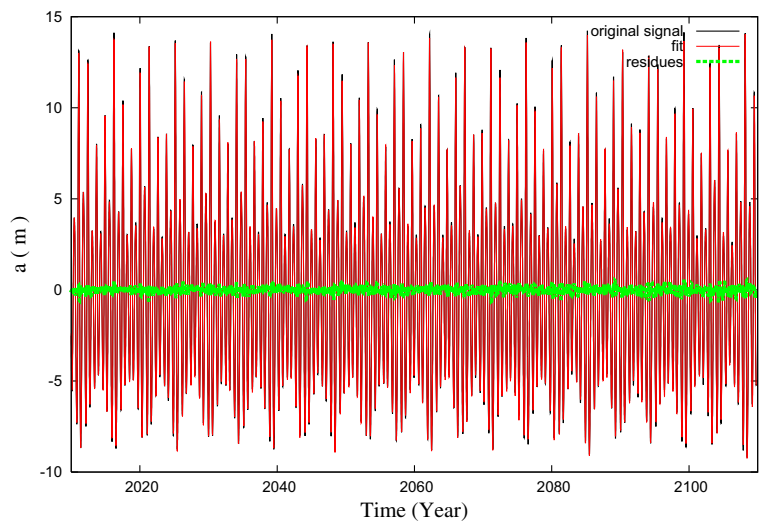

Fig. 9. Effects of Ceres on $a_{\mathrm{EMB}}$, for a $100 \mathrm{y}$ time interval, from JD 2009.81. Residuals (in green) after removing the sinusoidal components from the least-squares analysis.

sufficient for the purpose to multiply each number of Table 6 by the relative mass uncertainty $\Delta M / M$, whose value has been already given for each object in Table 1 . Because of its relatively large mass (17.7\% that of Ceres) and its very high mass uncertainty $(22.6 \%)$, the asteroid 111 Ate is by far the most problematic one, causing uncertainties higher than 93 times that of Ceres for $a_{\text {Mars }}, 197$ times for $a_{0} \Delta e_{\text {Mars }}, 44$ times for $i_{\text {Mars }}, 23$ times for $\Omega_{\text {Mars }}, 58$ times for $\varpi_{\text {Mars }}$ and 295 times for $\lambda_{\text {Mars }}$. Uncertainties on the same order can be observed for 6 Hebe (18.7\% mass uncertainty), 7 Iris (8.6\%), 9 Metis $(23.3 \%) 19$ Fortuna (14.0\%), 20 Massalia (16.9\%) and 46 Hestia (63\%). We think that a table such as Table 7 shows in a very straightforward manner for which asteroid observational campaigns should be launched to minimize errors in the Mars ephemeris.

\section{Perturbation on the EMB, Mercury and Venus}

In this section we carry out the same kind of study as in the previous section for the terrestrial planets other than Mars. Instead of the Earth isolated, we consider the EMB. This facilitates our calculations noticably. A specific study of the asteroidal effects on the Earth and the Moon taken individually is scheduled for a future paper.

\subsection{Effects on EMB}

As an example we show in Figs. 9-11 the effects of the gravitational action of Ceres, Pallas and Vesta on the EMB semi-major axis. They are characterized by very stable and regular leading oscillations with peak-to-peak amplitudes about $25 \mathrm{~m}$ for Ceres, $9 \mathrm{~m}$ for Pallas and $15 \mathrm{~m}$ for Vesta. The flat curves in each figure represent the residuals after substracting the fit with the help of Fourier and Poisson components. We were able to reconstruct the curve of Ceres with as many as 50 frequencies. The leading components are shown in Table 8. We note that the amplitudes and periods of the leading oscillations are significantly shorter for the EMB than for Mars.

In Table 9 we present the peak-to-peak amplitudes of the effects of each asteroid on the orbital parameters of the EMB for a 1000 y time interval. They are generally, but no systematically smaller than the corresponding effect on Mars. This is because the mass of Mars is much smaller than the mass of our planet $\left(M_{\text {Mars }} / M_{\text {Earth }} \approx 0.107\right)$ and its orbit is much closer to the asteroid main belt. 
Table 6. Peak-to-peak amplitudes of the variations of the six Mars orbital elements for a $1000 \mathrm{y}$ time interval starting from JD 2009.81.

\begin{tabular}{|c|c|c|c|c|c|c|c|}
\hline & asteroid & $\begin{array}{r}\Delta a \\
\mathrm{~m}\end{array}$ & $\begin{array}{r}\Delta e \times a_{\mathrm{Mars}} \\
\mathrm{m}\end{array}$ & $\begin{array}{r}\Delta i \\
\times 10^{-6 \prime \prime}\end{array}$ & $\begin{array}{r}\Delta \Omega \\
\times 10^{-6 \prime \prime}\end{array}$ & $\begin{array}{r}\Delta \varpi \\
\times 10^{-6 \prime \prime}\end{array}$ & $\begin{array}{r}\Delta \lambda \\
\times 10^{-6 \prime \prime}\end{array}$ \\
\hline 1 & Ceres & 415.976 & 1300.018 & 6764.552 & 409910.423 & 101767.790 & 197860.644 \\
\hline 2 & Pallas & 212.853 & 2025.012 & 4517.624 & 110490.432 & 21951.167 & 143118.437 \\
\hline 3 & Juno & 38.999 & 166.213 & 381.803 & 8282.676 & 1641.266 & 24833.521 \\
\hline 4 & Vesta & 546.665 & 4665.960 & 5665.561 & 98770.967 & 50554.943 & 623437.866 \\
\hline 6 & Hebe & 144.013 & 607.501 & 606.177 & 2122.292 & 6015.502 & 40524.178 \\
\hline 7 & Iris & 67.551 & 589.408 & 77.461 & 11921.764 & 1707.940 & 3249.652 \\
\hline 8 & Flora & 28.615 & 351.759 & 264.020 & 1527.953 & 1472.282 & 23161.386 \\
\hline 9 & Metis & 68.308 & 608.089 & 96.367 & 10037.872 & 5999.291 & 6453.236 \\
\hline 10 & Hygiea & 53.587 & 547.873 & 225.513 & 13260.778 & 5733.690 & 6918.631 \\
\hline 11 & Parthenope & 8.210 & 65.473 & 76.711 & 197.072 & 688.702 & 2268.556 \\
\hline 13 & Egeria & 14.479 & 57.479 & 77.631 & 15907.661 & 1666.410 & 6619.356 \\
\hline 14 & Irene & 14.634 & 79.531 & 122.264 & 5390.858 & 1888.597 & 11809.004 \\
\hline 15 & Eunomia & 41.963 & 416.526 & 593.602 & 16346.103 & 1348.323 & 48827.323 \\
\hline 16 & Psyche & 10.560 & 135.172 & 101.183 & 2213.723 & 824.135 & 6357.709 \\
\hline 17 & Thetis & 2.740 & 23.640 & 20.280 & 38.826 & 173.695 & 1944.757 \\
\hline 18 & Melpomene & 6.828 & 57.461 & 138.647 & 1381.789 & 195.621 & 497.143 \\
\hline 19 & Fortuna & 48.578 & 308.680 & 30.604 & 3799.559 & 1832.499 & 46311.253 \\
\hline 20 & Massalia & 80.479 & 238.095 & 9.043 & 2019.272 & 2971.102 & 47763.291 \\
\hline 21 & Lutetia & 6.698 & 48.954 & 10.871 & 207.539 & 516.701 & 7525.555 \\
\hline 22 & Kalliope & 2.682 & 36.025 & 21.367 & 3708.021 & 401.749 & 1934.839 \\
\hline 24 & Themis & 14.250 & 50.778 & 1.832 & 527.693 & 1237.710 & 16186.184 \\
\hline 28 & Bellona & 16.140 & 74.403 & 214.068 & 1144.324 & 2820.137 & 7919.977 \\
\hline 29 & Amphitrite & 17.267 & 165.764 & 224.757 & 2016.979 & 2826.971 & 12679.011 \\
\hline 31 & Euphrosyne & 13.346 & 56.216 & 54.024 & 3639.611 & 482.373 & 6169.238 \\
\hline 45 & Eugenia & 8.092 & 107.311 & 202.524 & 1652.153 & 1867.647 & 2507.753 \\
\hline 46 & Hestia & 20.516 & 229.351 & 112.954 & 5941.046 & 1115.982 & 11354.487 \\
\hline 47 & Aglaja & 0.743 & 4.292 & 10.767 & 84.131 & 29.633 & 59.064 \\
\hline 48 & Doris & 4.005 & 28.678 & 58.280 & 2075.386 & 802.772 & 969.684 \\
\hline 49 & Pales & 1.635 & 27.457 & 5.568 & 440.772 & 120.879 & 210.067 \\
\hline 52 & Europa & 9.826 & 68.303 & 131.673 & 607.090 & 1828.279 & 13298.494 \\
\hline 65 & Cybele & 3.061 & 33.727 & 37.098 & 520.461 & 303.235 & 2904.304 \\
\hline 87 & Sylvia & 1.974 & 7.763 & 16.837 & 2297.924 & 229.907 & 419.793 \\
\hline 88 & Thisbe & 7.671 & 48.380 & 54.682 & 3342.237 & 256.270 & 6600.855 \\
\hline 90 & Antiope & 0.866 & 4.080 & 0.385 & 4.311 & 34.948 & 628.948 \\
\hline 107 & Camilla & 3.072 & 6.013 & 58.238 & 1078.727 & 503.130 & 278.376 \\
\hline 111 & Ate & 218.942 & 1425.543 & 1683.832 & 53568.836 & 33425.288 & 328096.755 \\
\hline 121 & Hermione & 1.001 & 11.230 & 4.441 & 587.147 & 95.005 & 1318.865 \\
\hline 130 & Elektra & 4.738 & 23.884 & 110.486 & 393.899 & 589.786 & 3224.094 \\
\hline 165 & Loreley & 12.197 & 52.039 & 256.157 & 5936.699 & 937.680 & 901.986 \\
\hline 189 & Phthia & 0.132 & 0.395 & 0.255 & 21.056 & 7.059 & 152.358 \\
\hline 243 & Ida & 0.108 & 0.116 & 0.049 & 3.560 & 3.224 & 28.511 \\
\hline 253 & Mathilde & 0.193 & 0.395 & 1.320 & 42.175 & 12.877 & 224.965 \\
\hline 283 & Emma & 0.486 & 4.920 & 9.306 & 230.447 & 22.563 & 56.147 \\
\hline
\end{tabular}

\subsection{Effects on Mercury and Venus}

The effects of the asteroids on the orbital parameters of the two internal planets Mercury and Venus are presented in Tables 10 and 11 also for a $1000 \mathrm{y}$ time span. The peak-to-peak amplitudes for $a_{\text {Mercury }}$ and $a_{\text {Venus }}$ do not exceed $1 \mathrm{~m}$ and $10 \mathrm{~m}$, i.e. roughly 400 times and 40 times less than for $a_{\text {Mars }}$. Nevertheless, the ratio is significantly lower for other parameters, also because of the predominance of long-term components, which can be characterized by quadratic or polynomial expressions in the interval of time considered.

\section{Influences of asteroid on the EMB-Mars distance and Mars orientation}

In view of the ground-based observations of Mars, the fundamental parameters are both the distance $d_{\text {Mars }}$ from the Earth geocenter (or the EMB in an alternative case considered here) to the planet geocenter, and the geocentric direction of the planet generally given through the set of its geocentric coordinates $\left(\alpha_{\text {Mars }}, \delta_{\text {Mars }}\right)$. Thus the gravitational effect of a given asteroid on these parameters comes directly from the combination of the influences of the asteroid on the orbital elements of the EMB and the planet, which we studied above. As for these influences, the uncertainty of the asteroid masses directly affects the accuracy of the determination of $d_{\text {Mars }}, \alpha_{\text {Mars }}$ and $\delta_{\text {Mars }}$. Moreover, the analytical characterization of the asteroidal effects on these three geocentric parameters is still much more complicated than for the heliocentric orbital parameters, because the determination of the vector from the EMB to planet, even assuming that the two bodies follow a Keplerian trajectory, is a much more complex function that involves Legendre polynomials, than for the heliocentric vector of the planet.

We recall that to facilitate the computations, we replaced the Moon and the Earth by the EMB, i.e. a single point whose mass is the sum of the masses of the two bodies, and which is located at their barycenter. We will calculate in a future paper the differential effects of our asteroids on the Earth to Moon distance, 
Table 7. Uncertainty on the values of the six Mars orbital elements, for a $1000 \mathrm{y}$, because of the lack of accuracy in the measurements of the asteroid mass.

\begin{tabular}{|c|c|c|c|c|c|c|c|}
\hline & Asteroid & $\begin{array}{r}\Delta a \\
{[\mathrm{~m}]}\end{array}$ & $\Delta e \times a_{\text {Mars }}$ & $\begin{array}{r}\Delta i \\
\times 10^{-6 \prime \prime}\end{array}$ & $\begin{array}{r}\Delta \Omega \\
\times 10^{-6 \prime \prime}\end{array}$ & $\begin{array}{r}\Delta \varpi \\
\times 10^{-6 \prime \prime}\end{array}$ & $\begin{array}{r}\Delta \lambda \\
\times 10^{-6 \prime \prime}\end{array}$ \\
\hline 1 & Ceres & 0.529 & 1.653 & 8.599 & 521.073 & 129.366 & 251.518 \\
\hline 2 & Pallas & 1.451 & 13.802 & 30.792 & 753.100 & 149.618 & 975.491 \\
\hline 3 & Juno & 7.800 & 33.243 & 76.361 & 1656.535 & 328.253 & 4966.704 \\
\hline 4 & Vesta & 1.220 & 10.415 & 12.646 & 220.471 & 112.846 & 1391.602 \\
\hline 6 & Hebe & 26.943 & 113.656 & 113.409 & 397.056 & 1125.430 & 7581.599 \\
\hline 7 & Iris & 13.510 & 117.882 & 15.492 & 2384.353 & 341.588 & 649.930 \\
\hline 8 & Flora & 3.023 & 37.158 & 27.890 & 161.404 & 155.523 & 2446.625 \\
\hline 9 & Metis & 15.917 & 141.691 & 22.455 & 2338.922 & 1397.893 & 1503.667 \\
\hline 10 & Hygiea & 1.771 & 18.102 & 7.451 & 438.131 & 189.439 & 228.589 \\
\hline 11 & Parthenope & 0.156 & 1.243 & 1.457 & 3.742 & 13.077 & 43.074 \\
\hline 13 & Egeria & 2.825 & 11.215 & 15.148 & 3103.934 & 325.153 & 1291.582 \\
\hline 14 & Irene & 2.587 & 14.058 & 21.611 & 952.864 & 333.820 & 2087.306 \\
\hline 15 & Eunomia & 1.998 & 19.835 & 28.267 & 778.386 & 64.206 & 2325.111 \\
\hline 16 & Psyche & 1.392 & 17.813 & 13.334 & 291.731 & 108.607 & 837.838 \\
\hline 17 & Thetis & 0.284 & 2.452 & 2.104 & 4.027 & 18.017 & 201.725 \\
\hline 18 & Melpomene & 2.306 & 19.408 & 46.828 & 466.697 & 66.071 & 167.909 \\
\hline 19 & Fortuna & 6.824 & 43.364 & 4.299 & 533.764 & 257.431 & 6505.832 \\
\hline 20 & Massalia & 13.635 & 40.338 & 1.532 & 342.108 & 503.369 & 8092.128 \\
\hline 21 & Lutetia & 0.623 & 4.554 & 1.011 & 19.306 & 48.065 & 700.052 \\
\hline 22 & Kalliope & 0.066 & 0.885 & 0.525 & 91.106 & 9.871 & 47.539 \\
\hline 24 & Themis & 5.404 & 19.255 & 0.695 & 200.095 & 469.326 & 6137.619 \\
\hline 28 & Bellona & 4.612 & 21.258 & 61.162 & 326.950 & 805.754 & 2262.851 \\
\hline 29 & Amphitrite & 6.044 & 58.018 & 78.665 & 705.943 & 989.440 & 4437.654 \\
\hline 31 & Euphrosyne & 2.516 & 10.597 & 10.184 & 686.061 & 90.927 & 1162.892 \\
\hline 45 & Eugenia & 2.698 & 35.770 & 67.508 & 550.718 & 622.549 & 835.918 \\
\hline 46 & Hestia & 12.799 & 143.081 & 70.467 & 3706.341 & 696.209 & 7083.534 \\
\hline 47 & Aglaja & 0.293 & 1.693 & 4.248 & 33.190 & 11.690 & 23.301 \\
\hline 48 & Doris & 1.970 & 14.104 & 28.663 & 1020.682 & 394.806 & 476.894 \\
\hline 49 & Pales & 0.303 & 5.085 & 1.031 & 81.624 & 22.385 & 38.901 \\
\hline 52 & Europa & 2.225 & 15.466 & 29.815 & 137.466 & 413.986 & 3011.237 \\
\hline 65 & Cybele & 0.734 & 8.087 & 8.896 & 124.801 & 72.713 & 696.421 \\
\hline 87 & Sylvia & 0.008 & 0.031 & 0.068 & 9.277 & 0.928 & 1.695 \\
\hline 88 & Thisbe & 2.240 & 14.125 & 15.965 & 975.793 & 74.820 & 1927.173 \\
\hline 90 & Antiope & 0.010 & 0.049 & 0.005 & 0.052 & 0.422 & 7.596 \\
\hline 107 & Camilla & 0.082 & 0.160 & 1.552 & 28.741 & 13.405 & 7.417 \\
\hline 111 & Ate & 49.523 & 322.444 & 380.867 & 12116.761 & 7560.482 & 74212.364 \\
\hline 121 & Hermione & 0.055 & 0.619 & 0.245 & 32.379 & 5.239 & 72.732 \\
\hline 130 & Elektra & 0.285 & 1.439 & 6.656 & 23.729 & 35.529 & 194.223 \\
\hline 165 & Loreley & 7.623 & 32.525 & 160.098 & 3710.437 & 586.050 & 563.742 \\
\hline 189 & Phthia & 0.045 & 0.135 & 0.087 & 7.206 & 2.416 & 52.144 \\
\hline 243 & Ida & 0.005 & 0.005 & 0.002 & 0.167 & 0.151 & 1.336 \\
\hline 253 & Mathilde & 0.008 & 0.017 & 0.056 & 1.788 & 0.546 & 9.536 \\
\hline 283 & Emma & 0.011 & 0.106 & 0.201 & 4.982 & 0.488 & 1.214 \\
\hline
\end{tabular}

which likely has some interesting implications on lunar laser ranging (LLR) measurements. We calculated the geocentric coordinates of Mars by simply substracting the heliocentric vector of the EMB from that of Mars. The effects of the leading asteroids Ceres, Pallas and Vesta on the EMB-Mars distance are plotted in Figs. 12-14. In any case the signal is dominated by a single wave with increasing amplitude and a period that slightly varies at each oscillation, which makes the adjusment through a leastsquares analysis uneasy, indeed even inadequate. As expected, the period is clearly close to the synodic period of the planet, which changes slightly at each synodic cycle. The increase of amplitudes with respect to the time are undoubtedly caused by the secular effects of the asteroid on the EMB and Mars orbital parameters, characterized by quadratic trends as studied in Sect. 4.3. These secular effects gradually enhance the effects on the EMB-Mars vector. The peak-to-peak amplitudes of the effects of Ceres, Pallas and Vesta on the EMB-to-Mars distance are, $34 \mathrm{~km}, 31 \mathrm{~km}$ and $116 \mathrm{~km}$ respectively during the $100 \mathrm{y}$ time interval considered.
In Figs. 15 and 16, we present the influence of Ceres on Mars geocentric right ascension and declination. Their peak-to-peak amplitudes reach 0.08 and 0.05 arcseconds during the $100 \mathrm{y}$ time interval. The peaks correspond to Mars oppositions, for which the relatively close distance of the planet from the Earth enhances the angular effects of the perturbations. In parallel we can observe the asymmetrical nature of the two curves originating from the fact that the effects are proportional to the distance from the Earth to Mars, which varies roughly from 0.5 to $2.5 \mathrm{AU}$.

\section{ASETEP database}

\subsection{Construction of the ASETEP database.}

As a result of all our computations, we constucted the ASETEP (asteroid effects on the terrestrial planets) database, which contains at its present extent the curves showing the individual effects of each of the 43 asteroids listed in Table 1 on each of the 6 orbital elements for any of the 4 terrestrial planets (Mercury, 
Table 8. Coefficients of Fourier and Poisson series for the effects of Ceres on $a_{\mathrm{EMB}}$.

\begin{tabular}{|c|c|c|c|c|c|c|c|c|c|}
\hline $\begin{array}{r}\text { Period } \\
\text { (Day) }\end{array}$ & $\begin{array}{l}\text { Period } \\
\text { (Year) }\end{array}$ & $\begin{array}{r}\text { SIN } \\
\times 10^{-2} \\
\end{array}$ & $\begin{array}{r}\mathrm{COS} \\
\times 10^{-2}\end{array}$ & $\times 10^{-1}$ & $\begin{array}{l}T \text { SIN } \\
\times 10^{-5}\end{array}$ & $\begin{array}{r}T \text { COS } \\
\times 10^{-5}\end{array}$ & $\times 10^{-5}$ & $\begin{array}{r}\text { Amplitud } \\
\times 10^{0}\end{array}$ & Asteroid \\
\hline 4264.15 & 11.67 & -5.833 & -4.725 & 0.751 & 4.218 & 4.478 & 6.332 & 0.089 & 1_Ceres \\
\hline 2785.82 & 7.63 & 14.760 & -17.093 & 2.258 & -9.642 & 14.800 & 20.930 & 0.164 & 1_Ceres \\
\hline 1048.02 & 2.87 & 14.503 & -23.187 & 2.735 & -13.280 & 16.173 & 22.872 & 0.199 & 1_Ceres \\
\hline 645.80 & 1.77 & 23.772 & 1.851 & 2.384 & 4.417 & 7.592 & 10.736 & 0.389 & 1_Ceres \\
\hline 583.74 & 1.60 & -4.586 & 80.143 & 8.027 & 2.322 & -39.840 & 56.342 & 0.048 & 1_Ceres \\
\hline 466.62 & 1.28 & -107.748 & 26.526 & 11.096 & -3.096 & -9.959 & 14.0 & 1.127 & 1_Ceres \\
\hline 399.51 & 1.09 & -1.046 & 24.761 & 2.478 & -0.533 & -9.255 & 13.089 & 0.106 & 1_Ceres \\
\hline 365.29 & 1.00 & 2.167 & 4.551 & 0.504 & 1.556 & -0.782 & 1.106 & 0.131 & 1_Ceres \\
\hline 337.45 & 0.92 & 0.631 & 7.730 & 0.776 & -0.767 & -3.066 & 4.336 & 0.080 & 1_Ceres \\
\hline 322.86 & 0.88 & 8.798 & 48.792 & 4.958 & 1.456 & -5.255 & 7.431 & 0.358 & 1_Ceres \\
\hline 312.83 & 0.86 & 7.583 & -2.635 & 0.803 & -4.257 & 0.966 & 1.366 & 0.216 & 1_Ceres \\
\hline 299.95 & 0.82 & -6.889 & 11.029 & 1.300 & 5.119 & -5.229 & 7.395 & 0.294 & 1_Ceres \\
\hline 291.95 & 0.80 & 24.131 & 76.178 & 7.991 & -12.129 & -38.203 & 54.027 & 0.144 & 1_Ceres \\
\hline 281.05 & 0.77 & 9.514 & -6.059 & 1.128 & -2.537 & 2.629 & 3.718 & 0.399 & 1_ Ceres \\
\hline 273.99 & 0.75 & -51.020 & -30.936 & 5.967 & 25.466 & 14.530 & 20.548 & 0.519 & 1_ Ceres \\
\hline ITUDE & & ore $=22.94$ & 527 & & $\mathrm{er}=0.35$ & & & & \\
\hline
\end{tabular}

Notes. Bias: $0.561802 \times 10^{+3}$; linear: $-0.549138 ; T^{2}: 0.133527 \times 10^{-3}$. The next-to-last column indicates the peak-to-peak amplitude of the total mixed component for the $100 \mathrm{y}$ time interval.

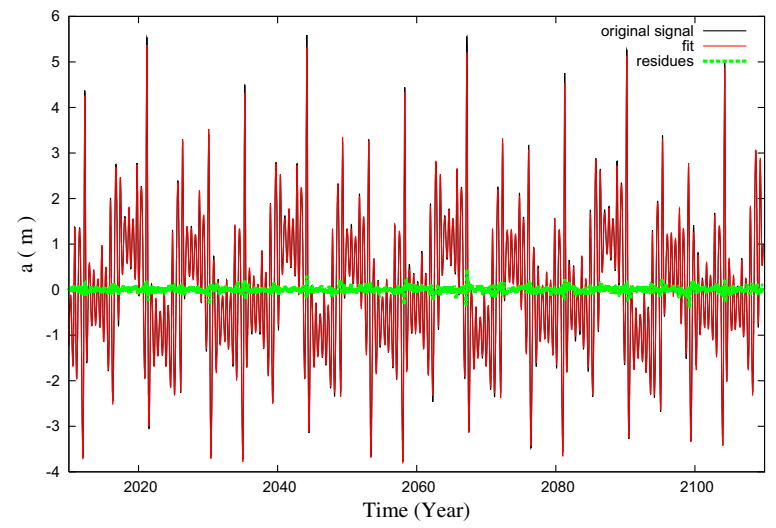

Fig. 10. Effects of Pallas on $a_{\mathrm{EMB}}$, for a $100 \mathrm{y}$ time interval, from JD 2009.81. Residuals (in green) after removing the sinusoidal components from the least-squares analysis.

Venus, the EMB, Mars) both for a 100 y time interval and a 1000 y time interval from JD 2009,7. In parallel we deliver for each of the curves the corresponding tables giving the Fourier and Poisson components for fitting these curves. This ASETEP database will be subject to regular and continuous updates with an increasing number of new asteroids taken into account, if their mass is determined with a satisfactory accuracy, i.e. better than $65 \%$ uncertainty, as for the 43 asteroids listed in Table 1 . One of the advantages of the ASETEP database is that the figures and tables already produced for a given asteroid can be updated immediately each time a new and more accurate determination of the mass of this asteroid is reached, by simple proportionnality.

\subsection{Individual and combined asteroidal effects}

In all computations we considered the effect of each asteroid taken individually, which neglects the effects from the combined gravitational attraction of the asteroids themselves. A priori these effects which result principally from the reciprocal gravitational interactions of the asteroids affecting their positions, are of second order because of the smallness of asteroid masses. They can be neglected at first approximation as long as

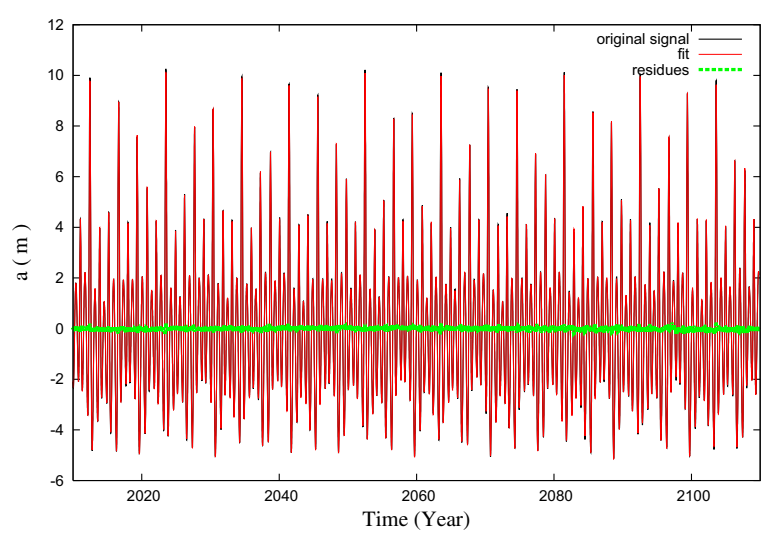

Fig. 11. Effects of Vesta on $a_{\mathrm{EMB}}$, for a $100 \mathrm{y}$ time interval, from JD 2009.81. Residuals (in green) after removing the sinusoidal components from the least-squares analysis.

the interval of time of the study $\Delta t$ is short, as for $\Delta t=100 \mathrm{y}$. To obtain some information about the error caused by neglecting the effects due to the combination of asteroids, we carried out a test with numerical integration: it consists of studying the difference between two numerical computations: first we summed up the individual effects of the 43 asteroids considered here on the Mars orbital parameters, each of which was obtained in the frame of an $n$-body problem with $n=10$ (Sun +8 planets + asteroid); second we included all asteroids in the frame of an n-body problem with $n=52$ (Sun +8 planets +43 asteroids).

In Fig. 17, we plot the combined effect of the 43 asteroids taken together on the Mars semi-major axis. The residuals of the two computation methods presented above do not exceed $2.5 \mathrm{~m}$ peak-to-peak, as can be seen in Fig. 18. This is by two orders less than the signal itself (650 m peak-to-peak), and the error caused by treating individual effects separately can be neglected in first approximation. This is still true for the other Mars parameters (see Appendix B), for which the errors are below $1.2 \times 10^{-11}$ for $e$ (Figs. B.1 and B.2), 1.8 mas for $i$ (Figs. B.3 and B.4), $10^{-2}$ mas for $\Omega$ (Figs. B.5 and B.6), $5 \times 10^{-3}$ mas for $\tilde{\omega}$ (Figs. B.7 and B.8). 
S. Aljbaae and J. Souchay: Effects of the large asteroids on terrestrial planets

Table 9. Peak-to-peak amplitudes of the variations of the six EMB orbital elements due to each given asteroid for a $1000 \mathrm{y}$ time interval starting from JD 2009.81.

\begin{tabular}{|c|c|c|c|c|c|c|c|}
\hline & Asteroid & $\begin{array}{r}\Delta a \\
\mathrm{~m}\end{array}$ & $\begin{array}{r}\Delta e \times a_{\text {Earth }} \\
\text { m }\end{array}$ & $\begin{array}{r}\Delta i \\
\times 10^{-6 \prime \prime}\end{array}$ & $\begin{array}{r}\Delta \Omega \\
\times 10^{-6 \prime \prime}\end{array}$ & $\begin{array}{r}\Delta \varpi \\
\times 10^{-6 \prime \prime}\end{array}$ & $\begin{array}{r}\Delta \lambda \\
\times 10^{-6 \prime \prime}\end{array}$ \\
\hline 1 & Ceres & 25.443 & 543.236 & 4929.530 & 464926.356 & 6311.044 & 2882.002 \\
\hline 2 & Pallas & 10.608 & 147.959 & 219.655 & 1138450.592 & 2759.495 & 26618.466 \\
\hline 3 & Juno & 1.347 & 29.962 & 29.840 & 55190.496 & 1976.844 & 5736.100 \\
\hline 4 & Vesta & 19.679 & 221.168 & 1729.805 & 303243.082 & 55222.264 & 40243.056 \\
\hline 6 & Hebe & 1.575 & 44.829 & 128.567 & 66754.335 & 1169.070 & 2754.659 \\
\hline 7 & Iris & 1.916 & 49.911 & 67.099 & 5392.495 & 2470.755 & 2850.537 \\
\hline 8 & Flora & 1.141 & 36.128 & 61.188 & 13731.489 & 989.258 & 194.963 \\
\hline 9 & Metis & 1.324 & 23.418 & 97.963 & 18171.585 & 2828.013 & 301.391 \\
\hline 10 & Hygiea & 2.154 & 28.291 & 122.134 & 18072.496 & 6670.653 & 4666.845 \\
\hline 11 & Parthenope & 0.402 & 8.018 & 19.419 & 6613.715 & 1071.967 & 1323.398 \\
\hline 13 & Egeria & 0.647 & 6.346 & 114.239 & 52651.902 & 504.693 & 173.308 \\
\hline 14 & Irene & 0.624 & 17.746 & 52.094 & 3431.527 & 414.283 & 1124.330 \\
\hline 15 & Eunomia & 2.074 & 60.980 & 236.253 & 49917.699 & 1191.803 & 1711.442 \\
\hline 16 & Psyche & 1.673 & 37.652 & 18.645 & 13866.105 & 2789.469 & 7791.016 \\
\hline 17 & Thetis & 0.119 & 0.879 & 4.588 & 1577.995 & 306.011 & 204.078 \\
\hline 18 & Melpomene & 0.631 & 16.064 & 17.729 & 13773.197 & 234.733 & 1303.507 \\
\hline 19 & Fortuna & 1.107 & 30.447 & 8.395 & 5701.767 & 689.533 & 2320.502 \\
\hline 20 & Massalia & 0.688 & 1.965 & 1.549 & 1315.434 & 922.438 & 953.087 \\
\hline 21 & Lutetia & 0.235 & 6.677 & 7.069 & 685.747 & 598.547 & 132.662 \\
\hline 22 & Kalliope & 0.381 & 3.543 & 41.715 & 8466.995 & 239.465 & 775.256 \\
\hline 24 & Themis & 0.456 & 7.424 & 1.398 & 908.453 & 142.142 & 794.665 \\
\hline 28 & Bellona & 0.675 & 10.883 & 40.815 & 25052.303 & 1082.842 & 801.938 \\
\hline 29 & Amphitrite & 0.773 & 14.573 & 6.314 & 36621.458 & 577.161 & 632.069 \\
\hline 31 & Euphrosyne & 0.318 & 2.090 & 23.015 & 18359.137 & 122.700 & 67.111 \\
\hline 45 & Eugenia & 0.618 & 10.152 & 35.986 & 25097.892 & 1631.268 & 501.838 \\
\hline 46 & Hestia & 3.892 & 78.350 & 3.219 & 18091.046 & 4244.686 & 10698.904 \\
\hline 47 & Aglaja & 0.140 & 1.865 & 0.227 & 2219.030 & 223.737 & 84.944 \\
\hline 48 & Doris & 0.412 & 1.419 & 1.141 & 12170.155 & 138.494 & 549.257 \\
\hline 49 & Pales & 0.156 & 3.498 & 3.626 & 498.753 & 155.474 & 501.291 \\
\hline 52 & Europa & 0.569 & 4.259 & 41.151 & 14775.024 & 553.168 & 2008.514 \\
\hline 65 & Cybele & 0.349 & 1.907 & 8.621 & 5582.948 & 883.675 & 375.725 \\
\hline 87 & Sylvia & 0.350 & 3.944 & 33.215 & 6532.738 & 334.762 & 847.921 \\
\hline 88 & Thisbe & 0.704 & 11.842 & 32.942 & 2892.127 & 1809.126 & 1924.267 \\
\hline 90 & Antiope & 0.090 & 0.626 & 0.569 & 128.930 & 74.697 & 95.295 \\
\hline 107 & Camilla & 0.503 & 1.431 & 6.525 & 11211.884 & 73.744 & 476.956 \\
\hline 111 & Ate & 9.223 & 76.054 & 449.106 & 151257.961 & 12292.524 & 28037.019 \\
\hline 121 & Hermione & 0.192 & 2.596 & 9.092 & 1821.472 & 60.102 & 613.565 \\
\hline 130 & Elektra & 0.277 & 4.675 & 29.562 & 17655.726 & 232.881 & 840.610 \\
\hline 165 & Loreley & 1.280 & 5.862 & 102.851 & 29936.733 & 1867.874 & 974.511 \\
\hline 189 & Phthia & 0.056 & 0.036 & 0.066 & 62.766 & 3.047 & 179.217 \\
\hline 243 & Ida & 0.076 & 0.131 & 0.016 & 8.814 & 11.517 & 233.687 \\
\hline 253 & Mathilde & 0.069 & 0.386 & 0.016 & 231.658 & 24.807 & 92.696 \\
\hline 283 & Emma & 0.094 & 1.347 & 3.668 & 1093.080 & 54.125 & 181.180 \\
\hline
\end{tabular}

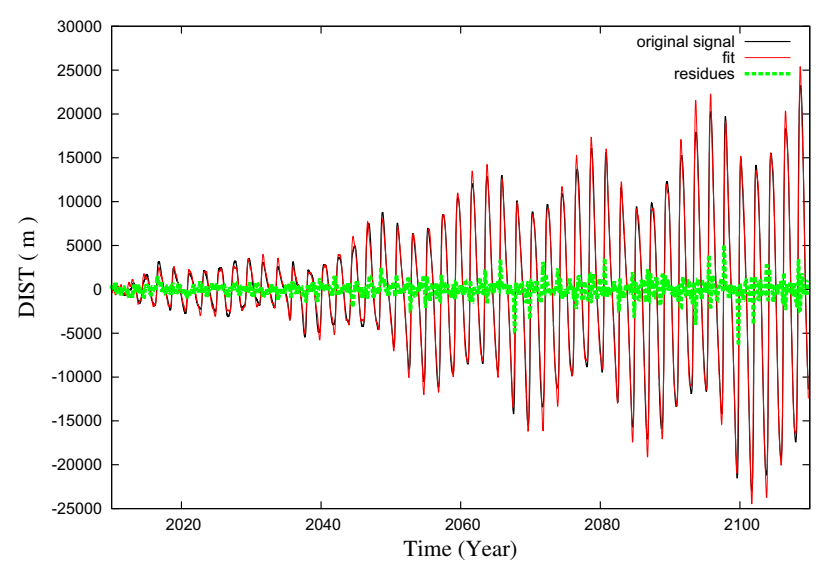

Fig. 12. Effects of Ceres on the distance from the EMB to Mars for a $100 \mathrm{y}$ time interval from JD 2009.81. The curve in green corresponds to the post-fit residuals.

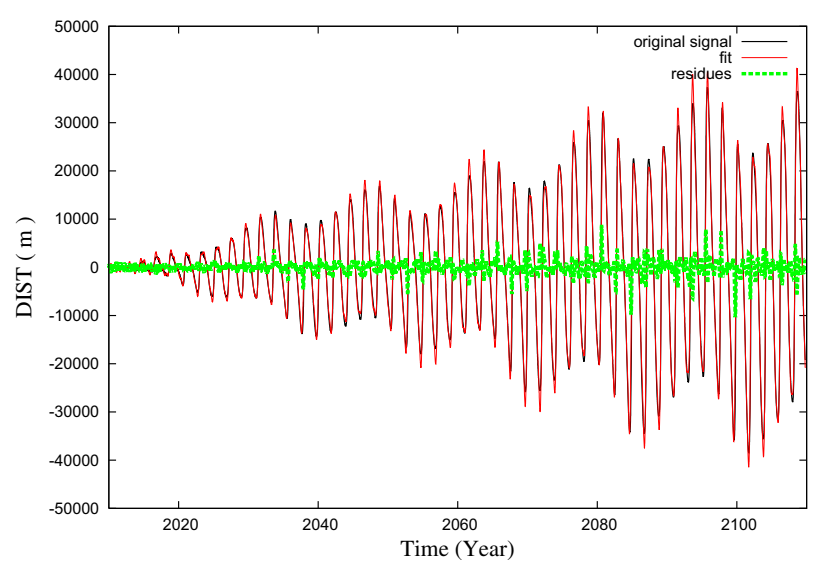

Fig. 13. Effects of Pallas on the distance from the EMB to Mars for a 100 y time interval from JD 2009.81. The curve in green corresponds to the post-fit residuals. 
Table 10. Peak-to-peak amplitudes of the variations of the six Mercury orbital elements due to each given asteroid for a $1000 \mathrm{y}$ time interval starting from JD 2009.81.

\begin{tabular}{|c|c|c|c|c|c|c|c|}
\hline & Asteroid & $\begin{array}{r}\Delta a \\
\mathrm{~m}\end{array}$ & $\begin{array}{r}\Delta e \times a_{\text {Mercury }} \\
\mathrm{m}\end{array}$ & $\begin{array}{r}\Delta i \\
\times 10^{-6 \prime \prime}\end{array}$ & $\begin{array}{r}\Delta \Omega \\
\times 10^{-6 \prime \prime}\end{array}$ & $\begin{array}{r}\Delta \varpi \\
\times 10^{-6 \prime \prime}\end{array}$ & $\begin{array}{r}\Delta \lambda \\
\times 10^{-6 \prime \prime}\end{array}$ \\
\hline 1 & Ceres & 1.027 & 17.040 & 506.486 & 1525.642 & 5274.314 & 1031.921 \\
\hline 2 & Pallas & 0.236 & 21.632 & 546.181 & 3524.193 & 680.519 & 2027.054 \\
\hline 3 & Juno & 0.031 & 0.226 & 23.731 & 194.155 & 53.392 & 1045.685 \\
\hline 4 & Vesta & 0.444 & 1.697 & 312.317 & 1284.460 & 2605.141 & 9801.069 \\
\hline 6 & Hebe & 0.035 & 1.712 & 38.624 & 149.068 & 85.198 & 742.517 \\
\hline 7 & Iris & 0.050 & 0.311 & 3.638 & 190.978 & 91.108 & 1633.283 \\
\hline 8 & Flora & 0.036 & 0.610 & 10.833 & 69.548 & 81.990 & 1386.485 \\
\hline 9 & Metis & 0.032 & 0.097 & 6.998 & 53.990 & 161.183 & 1166.247 \\
\hline 10 & Hygiea & 0.054 & 1.107 & 12.770 & 512.880 & 391.011 & 1769.981 \\
\hline 11 & Parthenope & 0.020 & 0.202 & 5.388 & 50.541 & 51.114 & 965.908 \\
\hline 13 & Egeria & 0.033 & 0.866 & 7.069 & 161.930 & 104.715 & 559.951 \\
\hline 14 & Irene & 0.043 & 0.472 & 6.181 & 2.022 & 61.844 & 2266.552 \\
\hline 15 & Eunomia & 0.046 & 1.757 & 38.713 & 391.935 & 218.771 & 398.350 \\
\hline 16 & Psyche & 0.037 & 0.389 & 9.404 & 146.207 & 111.991 & 868.428 \\
\hline 17 & Thetis & 0.021 & 0.015 & 1.276 & 9.532 & 10.570 & 1164.296 \\
\hline 18 & Melpomene & 0.024 & 0.282 & 6.566 & 45.892 & 22.050 & 776.751 \\
\hline 19 & Fortuna & 0.028 & 0.299 & 2.340 & 119.341 & 79.661 & 99.164 \\
\hline 20 & Massalia & 0.021 & 0.275 & 0.760 & 48.928 & 36.882 & 163.080 \\
\hline 21 & Lutetia & 0.023 & 0.194 & 0.909 & 16.061 & 22.953 & 380.720 \\
\hline 22 & Kalliope & 0.020 & 0.055 & 2.041 & 34.978 & 37.148 & 904.473 \\
\hline 24 & Themis & 0.035 & 0.325 & 0.393 & 43.222 & 44.341 & 2114.352 \\
\hline 28 & Bellona & 0.031 & 0.613 & 15.834 & 93.611 & 61.361 & 745.187 \\
\hline 29 & Amphitrite & 0.032 & 0.383 & 13.422 & 69.474 & 135.370 & 275.212 \\
\hline 31 & Euphrosyne & 0.015 & 0.351 & 5.117 & 60.569 & 13.988 & 107.380 \\
\hline 45 & Eugenia & 0.032 & 0.463 & 16.170 & 134.059 & 102.246 & 1300.468 \\
\hline 46 & Hestia & 0.056 & 0.989 & 8.991 & 226.888 & 156.690 & 2138.406 \\
\hline 47 & Aglaja & 0.019 & 0.084 & 0.771 & 6.255 & 11.698 & 333.500 \\
\hline 48 & Doris & 0.024 & 0.331 & 5.801 & 81.630 & 39.975 & 1628.596 \\
\hline 49 & Pales & 0.026 & 0.041 & 0.345 & 16.042 & 9.940 & 566.625 \\
\hline 52 & Europa & 0.032 & 0.298 & 11.911 & 65.363 & 66.695 & 1956.630 \\
\hline 65 & Cybele & 0.020 & 0.069 & 4.196 & 52.779 & 46.187 & 221.947 \\
\hline 87 & Sylvia & 0.026 & 0.165 & 1.920 & 18.840 & 41.512 & 869.579 \\
\hline 88 & Thisbe & 0.029 & 0.288 & 3.084 & 107.780 & 73.901 & 517.634 \\
\hline 90 & Antiope & 0.029 & 0.026 & 0.075 & 2.631 & 3.275 & 544.525 \\
\hline 107 & Camilla & 0.018 & 0.242 & 6.226 & 53.845 & 24.304 & 708.428 \\
\hline 111 & Ate & 0.195 & 4.328 & 93.162 & 1380.844 & 1113.267 & 1479.395 \\
\hline 121 & Hermione & 0.015 & 0.088 & 0.568 & 0.221 & 15.036 & 342.469 \\
\hline 130 & Elektra & 0.017 & 0.498 & 11.278 & 34.221 & 10.621 & 593.566 \\
\hline 165 & Loreley & 0.042 & 0.823 & 22.573 & 186.959 & 138.388 & 1484.663 \\
\hline 189 & Phthia & 0.019 & 0.017 & 0.024 & 0.565 & 0.252 & 792.788 \\
\hline 243 & Ida & 0.023 & 0.012 & 0.005 & 0.243 & 0.353 & 1287.098 \\
\hline 253 & Mathilde & 0.011 & 0.011 & 0.099 & 1.381 & 0.617 & 456.920 \\
\hline 283 & Emma & 0.012 & 0.043 & 0.732 & 8.355 & 5.916 & 591.482 \\
\hline
\end{tabular}

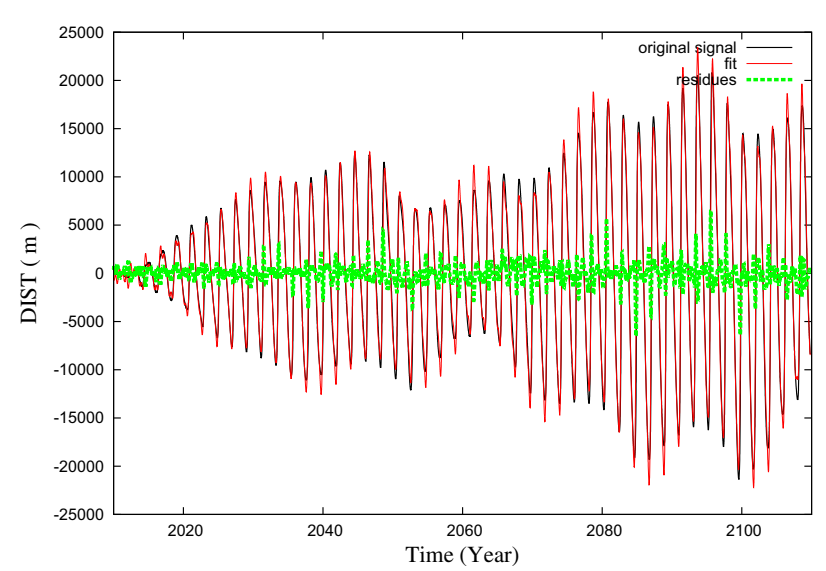

Fig. 14. Effects of Vesta on the distance from the EMB to Mars for a $100 \mathrm{y}$ time interval from JD 2009.81. The curve in green corresponds to the post-fit residuals.

\subsection{Use of ASETEP for ephemerides study}

Most of these asteroids have a very large mass uncertainty, sometimes by far exceeding their nominal values, which is why it appears to be ill-advised to include them individually in the ephemerides computations. But they can be assigned a reasonable distribution of masses according to some models such as the statistical asteroid model (Tedesco et al. 2005). The problem of mass undetermination of small asteroids was there partly solved by replacing all asteroids except for the 303 most perturbing ones by a ring. Through Monte Carlo experiments, where asteroids are assigned random but reasonable masses, it is possible to calculate the corresponding perturbations from the selected set of asteroids (Fienga et al. 2009) An estimate of the mass of the ring by Kuchynka et al. (2008) was $M_{\text {ring }}=1 \pm 0.3 \times 10^{-10} M_{\text {Sun }}$ for a ring at 3.14 AU. Yet compared this statistical evaluation, the uncertainty concerning the largest asteroids looks like a sever limitation for the ephemeris accuracy. For instance, the mass 
Table 11. Peak-to-peak amplitudes of the variations of the six Venus orbital elements due to the action of each asteroid for a $1000 \mathrm{y}$ time interval starting from JD 2009.81.

\begin{tabular}{|c|c|c|c|c|c|c|c|}
\hline & Asteroid & $\begin{array}{r}\Delta a \\
\mathrm{~m}\end{array}$ & $\begin{array}{r}\Delta e \times a_{\text {Venus }} \\
\mathrm{m}\end{array}$ & $\begin{array}{r}\Delta i \\
\times 10^{-6 \prime \prime}\end{array}$ & $\begin{array}{r}\Delta \Omega \\
\times 10^{-6 \prime \prime}\end{array}$ & $\begin{array}{r}\Delta \varpi \\
\times 10^{-6 \prime \prime}\end{array}$ & $\begin{array}{r}\Delta \lambda \\
\times 10^{-6 \prime \prime}\end{array}$ \\
\hline 1 & Ceres & 8.873 & 104.443 & 48.038 & 31824.583 & 36061.152 & 70697.133 \\
\hline 2 & Pallas & 3.622 & 42.975 & 1518.868 & 4481.157 & 2990.961 & 13040.604 \\
\hline 3 & Juno & 0.520 & 12.100 & 67.545 & 237.562 & 844.492 & 749.814 \\
\hline 4 & Vesta & 5.436 & 113.260 & 411.520 & 6658.590 & 35311.328 & 16328.430 \\
\hline 6 & Hebe & 0.363 & 12.581 & 87.162 & 486.578 & 2490.318 & 662.926 \\
\hline 7 & Iris & 0.647 & 17.653 & 1.688 & 902.456 & 2010.286 & 3453.414 \\
\hline 8 & Flora & 0.225 & 10.603 & 18.079 & 143.247 & 567.063 & 1067.780 \\
\hline 9 & Metis & 0.292 & 10.441 & 8.033 & 336.941 & 2196.530 & 174.656 \\
\hline 10 & Hygiea & 0.655 & 14.605 & 16.991 & 2080.629 & 4350.355 & 1846.343 \\
\hline 11 & Parthenope & 0.129 & 0.871 & 9.425 & 12.093 & 1109.277 & 555.197 \\
\hline 13 & Egeria & 0.239 & 0.504 & 53.465 & 939.036 & 928.800 & 2454.464 \\
\hline 14 & Irene & 0.179 & 4.529 & 2.946 & 292.024 & 649.127 & 210.247 \\
\hline 15 & Eunomia & 0.435 & 17.318 & 69.851 & 2515.550 & 1056.317 & 2316.562 \\
\hline 16 & Psyche & 0.681 & 8.146 & 18.972 & 245.119 & 1104.041 & 647.785 \\
\hline 17 & Thetis & 0.034 & 0.526 & 2.198 & 4.257 & 214.398 & 83.850 \\
\hline 18 & Melpomene & 0.191 & 4.177 & 16.546 & 5.985 & 669.946 & 832.947 \\
\hline 19 & Fortuna & 0.195 & 8.576 & 6.152 & 369.171 & 512.983 & 1946.517 \\
\hline 20 & Massalia & 0.176 & 1.709 & 1.578 & 146.463 & 923.534 & 881.744 \\
\hline 21 & Lutetia & 0.085 & 0.941 & 0.244 & 7.793 & 692.551 & 295.897 \\
\hline 22 & Kalliope & 0.113 & 1.642 & 6.392 & 315.607 & 171.884 & 98.980 \\
\hline 24 & Themis & 0.135 & 1.459 & 0.592 & 110.140 & 457.939 & 793.104 \\
\hline 28 & Bellona & 0.267 & 0.896 & 34.004 & 52.256 & 1521.361 & 1362.879 \\
\hline 29 & Amphitrite & 0.216 & 5.020 & 43.100 & 337.808 & 252.462 & 1806.797 \\
\hline 31 & Euphrosyne & 0.101 & 0.899 & 21.759 & 238.441 & 141.318 & 516.297 \\
\hline 45 & Eugenia & 0.169 & 4.213 & 33.420 & 75.524 & 850.141 & 667.179 \\
\hline 46 & Hestia & 0.652 & 13.456 & 21.361 & 588.879 & 3725.682 & 168.093 \\
\hline 47 & Aglaja & 0.085 & 0.211 & 2.609 & 23.395 & 250.509 & 277.676 \\
\hline 48 & Doris & 0.134 & 0.905 & 15.407 & 180.786 & 166.177 & 1191.363 \\
\hline 49 & Pales & 0.083 & 1.194 & 0.484 & 65.283 & 55.044 & 315.793 \\
\hline 52 & Europa & 0.153 & 0.666 & 21.136 & 112.815 & 824.430 & 911.623 \\
\hline 65 & Cybele & 0.119 & 0.888 & 7.796 & 66.585 & 786.489 & 359.006 \\
\hline 87 & Sylvia & 0.131 & 1.011 & 4.817 & 230.323 & 445.904 & 256.907 \\
\hline 88 & Thisbe & 0.261 & 0.760 & 3.815 & 476.506 & 1825.573 & 703.813 \\
\hline 90 & Antiope & 0.061 & 0.103 & 0.056 & 3.868 & 94.980 & 676.628 \\
\hline 107 & Camilla & 0.154 & 0.265 & 14.943 & 65.902 & 140.830 & 170.971 \\
\hline 111 & Ate & 2.328 & 15.164 & 198.173 & 6787.420 & 15143.916 & 10854.568 \\
\hline 121 & Hermione & 0.064 & 0.781 & 1.315 & 48.973 & 144.406 & 429.713 \\
\hline 130 & Elektra & 0.098 & 1.419 & 24.887 & 146.941 & 390.856 & 201.809 \\
\hline 165 & Loreley & 0.361 & 1.349 & 41.093 & 1179.523 & 1587.762 & 431.086 \\
\hline 189 & Phthia & 0.055 & 0.035 & 0.069 & 1.701 & 6.693 & 268.361 \\
\hline 243 & Ida & 0.086 & 0.105 & 0.014 & 0.812 & 29.902 & 879.399 \\
\hline 253 & Mathilde & 0.040 & 0.123 & 0.267 & 2.917 & 32.359 & 300.357 \\
\hline 283 & Emma & 0.063 & 0.319 & 1.421 & 46.358 & 89.405 & 437.905 \\
\hline
\end{tabular}

evaluation of asteroid 111 Ate is $0.84 \times 10^{-10} M_{\text {Sun }}$. This is very close to the evaluation of the mass of the ring above, and is accompanied by a $22 \%$ mass uncertainty (see Table 1 ). This is will cause a severe degradation of the accuracy in the Mars positioning in particular. To clearly demonstrate this degradation, we show in Fig. 19 the difference of the EMB-to-Mars distance from two types of planetary ephemeris DE405 (Standish 1998) and INPOP08 (Fienga et al. 2008). In the same figure we represent also the difference in the EMB-to-Mars distance due to the uncertainty on the sole mass of 111 Ate.

We point out the astonishing correspondence between the two curves in phase, frequency and amplitude. This suggests that the differences in the values of masses for this asteroid between the two ephemerides are highly responsible for their mutual discrepancy. For comparison we show in Figs. 20 to 22 the effects on the EMB-Mars distance of the mass uncertainty of 46 Hestia, 19 Fortuna, 1 Ceres, 2 Pallas, and 4 Vesta (Appendix C). We note that for these three last asteroids, which are the biggest ones, the effect is negligible, because of the very good mass accuracy. In contrast, for the first two the effect becomes clearly significant after a few years with an amplitude of roughly $1 / 8$ th and $1 / 16$ th that of 111 Ate (see Fig. 19) for a $100 \mathrm{y}$ time interval, that is to say, $2 \mathrm{~km}$ and $1 \mathrm{~km}$ instead of $16 \mathrm{~km}$.

In this context, our ASETEP database is an interesting and useful tool for understanding in a direct manner the limitations of modern ephemerides of terrestrial planets caused by the uncertainty on asteroid masses. It enables one to clearly indicate which asteroid would have to be observed preferentially in order to limitate its degradation on ephemeris accuracy. We limitated our study to a small sample of 43 asteroids for which the mass is known with relatively good accuracy, i.e. with less than $65 \%$ uncertainty, as we explained in Sect. 2. But we can easily extend this study to a much larger set of asteroids. To some extent our work is similar to that of Fienga et al. (2009), who constructed the INPOP08 planetary ephemeris: they also analyzed the individual effects of very many asteroids one by one, 


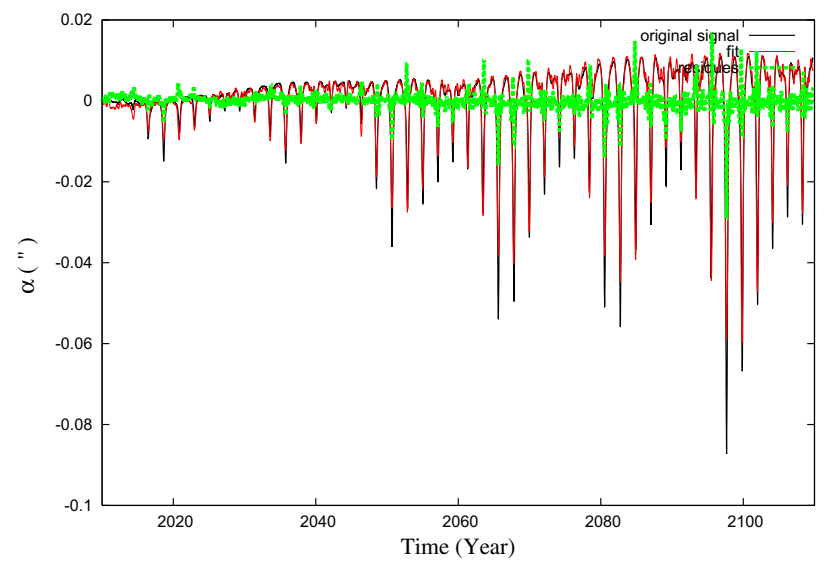

Fig. 15. Effects of Ceres on $\alpha_{\text {Mars }}$ for a $100 \mathrm{y}$ time interval from JD 2009.81. The curve in green corresponds to the post-fit residuals.

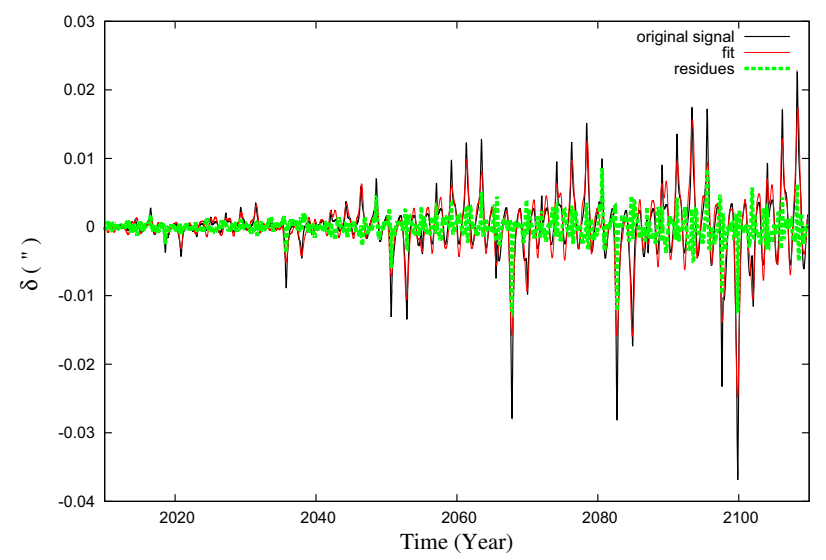

Fig. 16. Effects of Ceres on $\delta_{\text {Mars }}$ for a $100 \mathrm{y}$ time interval from JD 2009.81. The curve in green corresponds to a post-fit residuals.

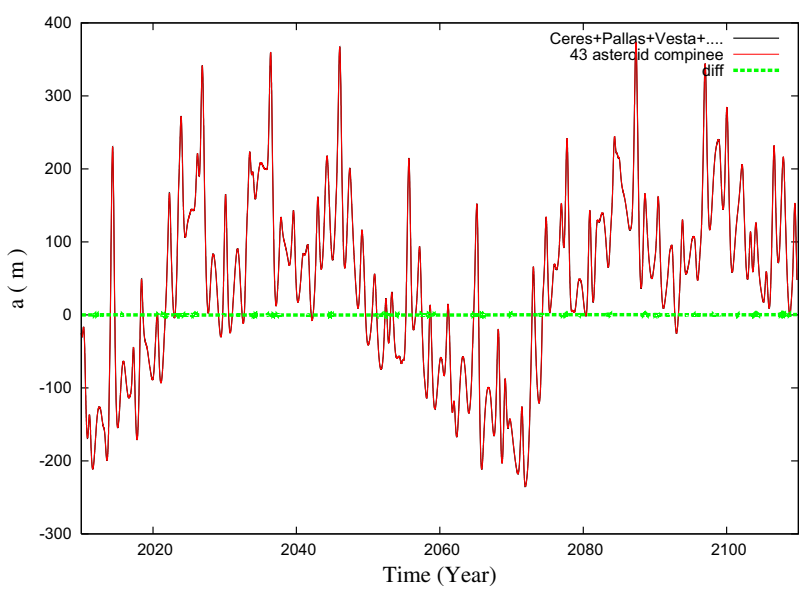

Fig. 17. Peak-to-peak amplitude of the combined effects of the 43 asteroids on $a_{\text {Mars }}$. The curve in green represents the difference between two ways of computation: adding individual perturbations, or making a combined integration.

but without carrying out a Fourier and Poisson series decomposition of each signal as we did, and without comparing this decomposition with specific studies (Williams 1984). Indeed, the great advantage of such a decomposition is to understand, at a given period (or frequency) range, which asteroid is dominant both in terms of amplitude (related to the mass $M$ ) and amplitude uncertainty (related to $\delta M / M$ ).

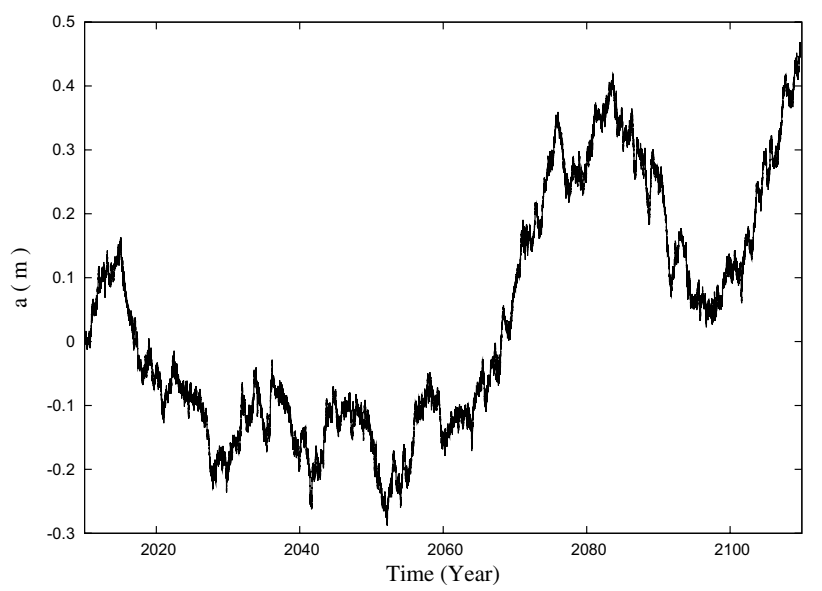

Fig. 18. Zoom of the green curve of Fig. 17, showing the difference between two ways of computation.

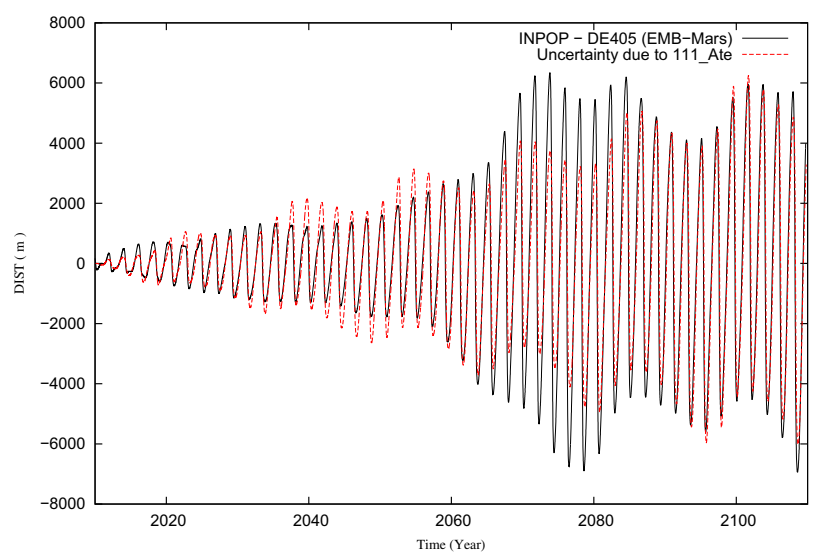

Fig. 19. Uncertainty of the EMB-to-Mars distance due to the lack of accuracy in Ate's mass (red curve) and difference in the EMB-to-Mars distance between DE405 and INPOP08 (black curve).

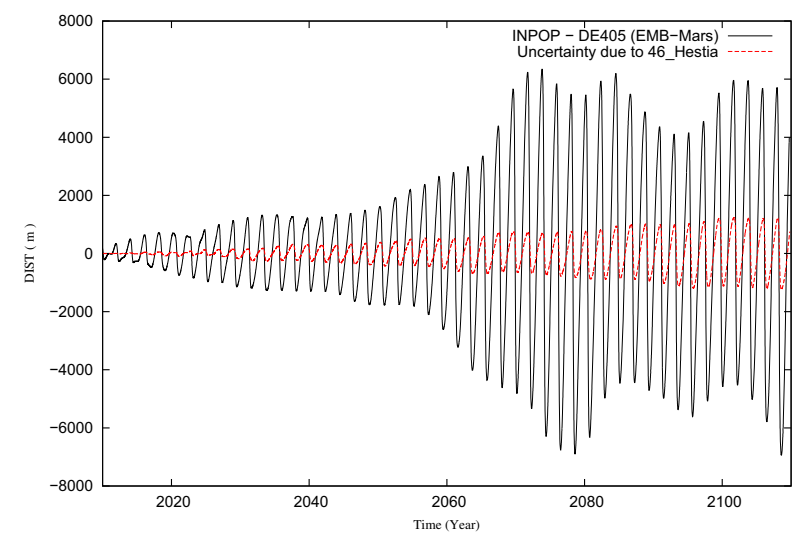

Fig. 20. Uncertainty of the EMB-to-Mars distance due to the lack of accuracy in Hestia's mass (red curve) and difference in the EMB-toMars distance between DE405 and INPOP08 (black curve).

Another use of ASETEP is the straightforward listing of asteroidal effects. In Table 12, we show the effects of the asteroid mass uncertainty on fundamental parameters such as the determination of the distance from the EMB to Mars, Venus and Mercury. For each planet, the value of the uncertainty on the EMP-to-planet distance is given in decreasing order of amplitude. The most problematic asteroids for Mars are 111 Ate, with a dramatic $139.0 \mathrm{~km}$ uncertainty, followed by 46 Hestia 


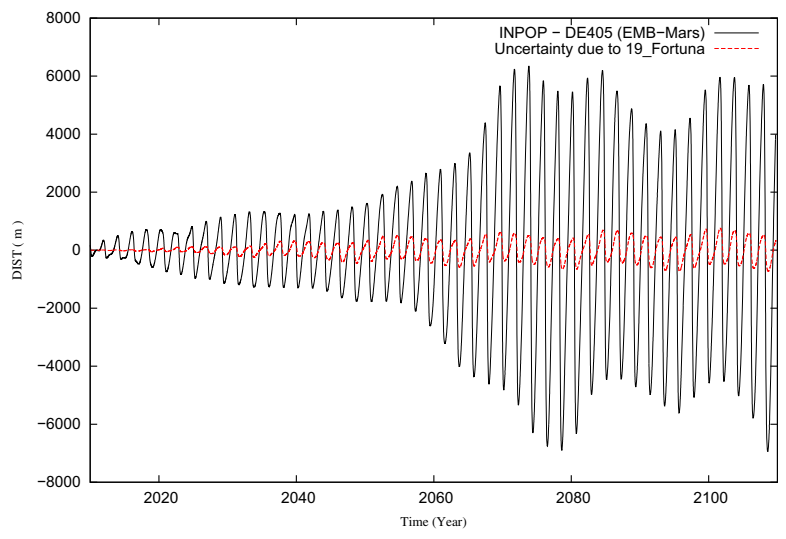

Fig. 21. Uncertainty of the EMB-to-Mars distance due to the lack of accuracy in Fortuna's mass (red curve) and difference in the EMB-toMars distance between DE405 and INPOP08 (black curve).

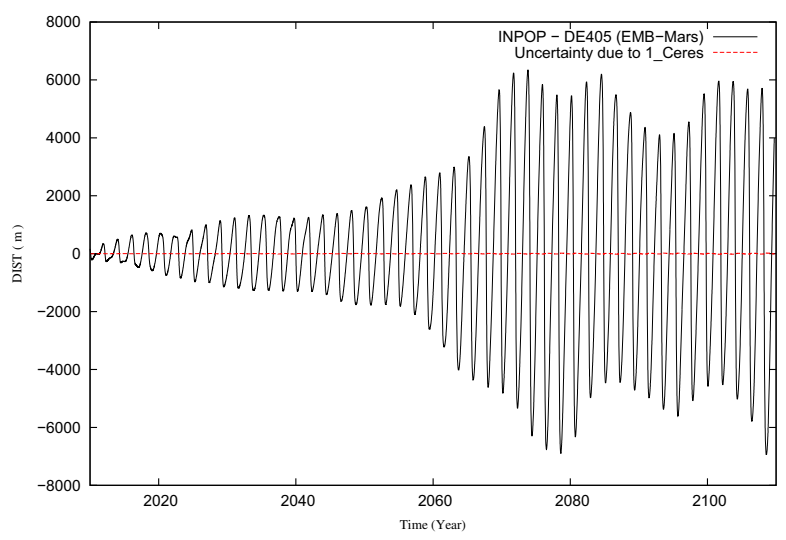

Fig. 22. Uncertainty of the EMB-to-Mars distance due to the lack of accuracy in Ceres' mass (red curve) and difference in the EMB-to-Mars distance between DE405 and INPOP08 (black curve).

(22.0 km), 20 Massilia (14.0 km), 19 Fortuna (12.1 km), and 3 Juno $(10.5 \mathrm{~km})$. In the case of Venus, 46 Hestia is dominant with a $7.2 \mathrm{~km}$ amplitude uncertainty, followed by 111 Ate $(4.2 \mathrm{~km}), 3$ Juno $(1.4 \mathrm{~km}), 7$ Iris $(1.3 \mathrm{~km})$ and 16 Psyche $(1.2 \mathrm{~km})$ The leading uncertainties for Mercury come from 111 Ate $(4.1 \mathrm{~km}), 46$ Hestia $(3.8 \mathrm{~km})$ and 165 Loreley $(0.9 \mathrm{~km})$. Additional information of ASETEP is the ratio of the amplitude of the uncertainty of Mars to that of Venus and Mercury, respectively. Because of the proximity of Mars to the asteroids this ratio would a priori be significantly higher by one or two orders. This is indeed what we can notice except for a few cases. The minimum and maximum values of the ratio are 0.15 (47 Aglaja) and 186.27 (19 Fortuna) respectively for Venus; they are 0.32 (47 Aglaja) and 224.54 (31 Euphrosyne) for Mercury.

In Fig. 23 we represent as a function of the mass of each of the 43 asteroids both the amplitude of its effect on the EMB-toMars distance and the amplitude of the uncertainty of determination of this effect. Clearly, if we exclude 111 Ate which offers by far the largest uncertainty, the following asteroids in decreasing amplitude of effects are not the largest ones but constitute a cluster with mass ranging between $3 \times 10^{-12} M_{S}$ and $3 \times 10^{-11} M_{S}$.

\section{Conclusion and prospects}

We have carried out detailed studies of the individual effects on the orbital parameters and geocentric positions of the terrestrial planets of a set of 43 of the most interesting asteroids,

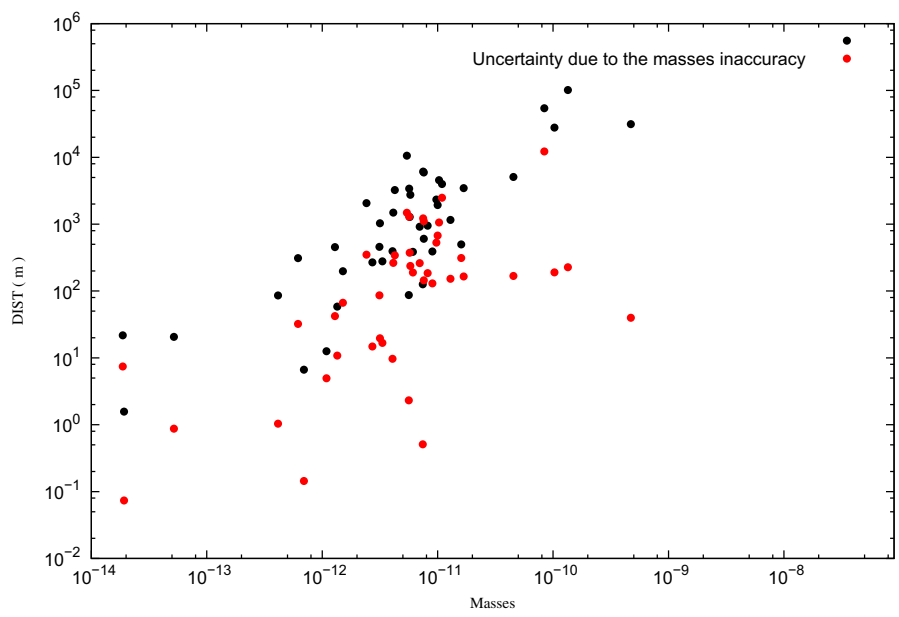

Fig. 23. Peak-to-peak effects (black circles) and respective uncertainty (red circles) of the EMB-to-Mars distance for each asteroid mass.

selected for their large mass and the relatively good accuracy of their mass determination, This continues previous research of Williams (1984) and Mouret et al. (2009) in a more systematic and extended way, These authors had restricted their results sole on the planet Mars and only two orbital parameters, i.e. $a_{\text {Mars }}$ and $\lambda_{\text {Mars. }}$.

1. In contrast to these authors we performed a purely numerical study, based on the numerical integration of the n-body problem. To validate our method, we compared our results for the effects of Ceres, Pallas, Vesta and other leading asteroids on $a_{\text {Mars }}$ and $\lambda_{\text {Mars }}$ with Mouret et al. (2009). We characterized the signals by a set of Fourier and Poisson series, whose arguments and amplitudes fit the analytical tables of Mouret et al. (2009) very well, which were constructed as a Fourier series as a function of the mean longitudes of Mars and the asteroids. This both validates our methodology and confirms the analytical tables of Williams (1984) and Mouret et al. (2009).

2. We extended our investigations to the other parameters $e_{\operatorname{mars}}$, $i_{\text {Mars }}, \Omega_{\text {Mars }}, \tilde{\omega}_{\text {Mars }}$, and we summarized in a table the amplitude of the effect of each asteroid, and the uncertainty on the modelisation of this effect directly proportional to the relative mass uncertainty $\Delta M_{\text {ast. }} / M_{\text {ast. }}$.

3. Moreover, we studied the other terrestrial planets Mercury, Venus and the Earth (the Earth-Moon barycenter) in the same way, gathering our results in recapitulative tables.

4. We also evaluated the influences of each asteroid on the equatorial coordinates $\alpha, \delta$ and the geocentric distance $d$ of the three terrestrial planets Mercury, Venus and Mars, as well as the uncertainty on these parameters that are directly linked to the mass uncertainty of each asteroid. Our results will be compared, with those obtained recently by Kuchynka et al. (2010), in the case of common asteroids.

5. All results of our study are gathered in the ASETEP database (asteroid effects on the terrestrial planets), i.e. the tables of the decomposition of the signals with the leading components of the fit as a function of Fourier and Poisson series, and also the curves showing the asteroid effects and the residuals after substraction of the fit. These tables are available only for a $1000 \mathrm{y}$ time span. The ASTEP database can be accessed at http://hpiers.obspm. fr/icrs-pc/. As a first step of construction of ASETEP we resticted our study on 
Table 12. Uncertainty of the distances Earth-Mercury, Earth-Venus, and Earth-Mars, due to the asteroids mass unaccuracy for a $1000 \mathrm{y}$ time interval.

\begin{tabular}{|c|c|c|c|c|c|c|c|}
\hline \multicolumn{2}{|c|}{ Mars } & \multicolumn{3}{|c|}{ Venus } & \multicolumn{3}{|c|}{ Mercury } \\
\hline Asteroide & EMB-Mars & Asteroide & EMB-Venus & Ratio & Asteroide & EMB-Mercury & Ratio \\
\hline 111_Ate & 139044.10 & 46_Hestia & 7184.52 & 3.07 & 111_Ate & 4073.74 & 34.13 \\
\hline 46_ Hestia & 22055.13 & 111 _Ate & 4188.84 & 33.19 & 46_Hestia & 3782.45 & 5.83 \\
\hline 20_ Massalia & 14016.59 & 3_Juno & 1399.89 & 7.55 & 165_L̄ Loreley & 916.20 & 0.86 \\
\hline 19_Fortuna & 12090.17 & 7_ Iris & 1334.75 & 0.85 & 3_Juno & 824.34 & 12.82 \\
\hline 3_Juno & 10566.12 & 16_Psyche & 1181.23 & 2.55 & 16_Psyche & 718.58 & 4.19 \\
\hline 24_Themis & 10531.30 & 165_Loreley & 931.12 & 0.84 & 48_Doris & 429.47 & 1.30 \\
\hline 6_Hebe & 9948.96 & 88_Thisbe & 806.58 & 5.23 & 88_ Thisbe & 428.74 & 9.85 \\
\hline 29_Amphitrite & 7805.64 & 18_Melpomene & 770.59 & 1.14 & 24_Themis & 409.79 & 25.70 \\
\hline 52_Europa & 5856.20 & 28_Bellona & 662.53 & 6.81 & 18_Melpomene & 391.27 & 2.24 \\
\hline 28_Bellona & 4510.37 & 13_Egeria & 468.42 & 5.07 & 6_Hebe & 283.14 & 35.14 \\
\hline 8_Flora & 4421.21 & 29_Amphitrite & 436.53 & 17.88 & 7_Iris & 249.36 & 4.53 \\
\hline 88_Thisbe & 4221.34 & 6_Hebe & 432.03 & 23.03 & 19_Fortuna & 220.82 & 54.75 \\
\hline 15_Eunomia & 4199.23 & 48_Doris & 335.68 & 1.66 & 189_Phthia & 214.23 & 0.83 \\
\hline 14_Irene & 3522.35 & 20_Massalia & 333.67 & 42.01 & 45_Eugenia & 213.72 & 6.66 \\
\hline 16_P̄syche & 3008.18 & 2_Pallas & 288.46 & 4.93 & 29_Amphitrite & 193.07 & 40.43 \\
\hline$\overline{9}$ _ Metis & 2772.05 & 52_Europa & 270.33 & 21.66 & 9_Metis & 182.47 & 15.19 \\
\hline 4_ Vesta & 2382.66 & 10_Hygiea & 235.19 & 1.22 & $14_{-}$Irene & 180.04 & 19.56 \\
\hline 13_Egeria & 2376.39 & 14_ Irene & 197.95 & 17.79 & 2_Pallas & 114.65 & 12.39 \\
\hline 31_Euphrosyne & 1995.00 & 65_C̄ Cybele & 184.85 & 7.53 & 20_Massalia & 104.96 & 133.55 \\
\hline 45_Eugenia & 1423.89 & 49_Pales & 156.28 & 0.65 & $\overline{52} \_$Europa & 100.20 & 58.45 \\
\hline 2_Pallas & 1420.99 & 4_ Vesta & 138.08 & 17.26 & 8_Flora & 98.61 & 44.84 \\
\hline 65_Cybele & 1391.56 & 47_Aglaja & 133.58 & 0.15 & 65_Cybele & 85.12 & 16.35 \\
\hline 21_Lutetia & 1211.49 & 45_Eugenia & 129.20 & 11.02 & 28_Bellona & 81.86 & 55.10 \\
\hline 7_ Iris & 1128.66 & 8_Flora & 103.45 & 42.74 & 17_ Thetis & 72.16 & 4.60 \\
\hline 18_Melpomene & 875.10 & 1_Ceres & 98.58 & 4.94 & 10_Hygiea & 70.72 & 4.05 \\
\hline 165_Loreley & 785.95 & 31_Euphrosyne & 95.83 & 20.82 & 13_Egeria & 63.56 & 37.39 \\
\hline 48_ Doris & 557.76 & 189_Phthia & 74.72 & 2.38 & 47_Aglaja & 61.06 & 0.32 \\
\hline 1_Ceres & 486.84 & 19_Fortuna & 64.90 & 186.27 & 15_Eunomia & 55.59 & 75.54 \\
\hline 130_Elektra & 402.76 & 24_Themis & 59.06 & 178.32 & 4_ Vesta & 46.54 & 51.19 \\
\hline 17_ Thetis & 332.10 & 9_Metis & 56.95 & 48.67 & 49_Pales & 46.45 & 2.19 \\
\hline 10_Hygiea & 286.44 & 243_Ida & 54.77 & 0.29 & 243 Ida & 46.23 & 0.34 \\
\hline 189_Phthia & 177.82 & 130_Elektra & 44.75 & 9.00 & 130_Elektra & 16.80 & 23.98 \\
\hline 121_ Hermione & 174.91 & 15_Eunomia & 36.12 & 116.25 & 21_Lutetia & 14.81 & 81.82 \\
\hline 11_Parthenope & 111.49 & 21_Lutetia & 25.10 & 48.27 & 121_ Hermione & 14.04 & 12.45 \\
\hline 22_Kalliope & 107.91 & 22_Kalliope & 19.96 & 5.41 & $25 \overline{3}_{-}$Mathilde & 12.39 & 1.14 \\
\hline 49_Pales & 101.64 & 11_Parthenope & 16.64 & 6.70 & 283_Emma & 10.60 & 0.49 \\
\hline 47__Aglaja & 19.69 & 253_Mathilde & 15.27 & 0.93 & 31_Euphrosyne & 8.88 & 224.54 \\
\hline 243_Ida & 15.80 & 17_ Thetis & 15.20 & 21.85 & 11_Parthenope & 7.98 & 13.98 \\
\hline 253_Mathilde & 14.17 & 283_Emma & 14.15 & 0.37 & 107_Camilla & 7.17 & 1.93 \\
\hline 107_Camilla & 13.81 & 107_Camilla & 13.15 & 1.05 & 22_Kalliope & 6.90 & 15.64 \\
\hline 90_Antiope & 13.21 & 121_ Hermione & 11.46 & 15.26 & 90_Antiope & 2.88 & 4.58 \\
\hline 87_Sylvia & 7.56 & 90_ Antiope & 7.92 & 1.67 & 1_Ceres & 2.43 & 200.25 \\
\hline 283_Emma & 5.21 & 87_Sylvia & 4.36 & 1.73 & 87_Sylvia & 1.40 & 5.38 \\
\hline
\end{tabular}

Notes. The third clumn for Mercury and Venus indicates the ratio of the effect with respect to the corresponding effect on Mars.

a limited set of 43 asteroids. But one of the advantages of this database is that it is generated automatically and can be updated each time a new and more accurate determination of the masses of selected asteroids is made or when a new asteroid is included. The ASETEP database enables one to characterize the influence of each asteroid on the orbital motion of the terrestrial planets in an accurate and detailed manner, and will guide the efforts toward improvements of the ephemeris. The case of 111 Ate is particularly significant, because we were able to show that the differences given by two types of ephemerides (DE405 and IPOP08) on the EMB-Mars distance is remarkably similar to the effect caused by the mass uncertainty on this asteroid, which suggests the choice of two different masses for 111 Ate in the ephemeris given above.
Acknowledgements. This work is supported for the first author by a Ph.D. fellowship from the Damsacus University, Syria.

\section{References}

Aslan, Z., Gumerov, R., Hudkova, L., et al. 2007, ASP Conf. Ser., 370 Baer, J., URL: http://home.earthlink.net/ jimbaer1/astmass.htm Baer, J., \& Chesley, R. S. 2008a, Cel. Mech. Dyn. Astr., 100, 27

Baer, J., Milani, A., Chesley, S., \& Matson, R. D. 2008b, DPS meeting, 40, 493 Bange, J. 1998, A\&A, 340, L1

Bange, J. F., \& Bec-Borsenberger, A. 1997, ESA, 402, 169

Bretagnon, P. \& Francou, G. 1987, A\&A, 202, 309

Brouwer, D., \& Clemence, G. M. 1961, Methods of Celestial Mechanics (New York: Acadimic Press)

Chapront-Touzé, M., \& Chapront, J. 1988, A\&A, 190, 342

Fienga, A., Manche, H., Laskar, J., \& Gastineau, M. 2008, A\&A, 477, 315 
S. Aljbaae and J. Souchay: Effects of the large asteroids on terrestrial planets

Fienga, A., Laskar, J., Morley, T, et al. 2009, A\&A, 507, 1675

Hilton, J. L. 1999, AJ, 117, 1077

Ivantsov, A. 2008, Planet. Space Sci., 56, 1857

Kochetova, O. M. 2004, Sol. Syst. Res., 38, 66

Kuchynka, P. 2010, Observatoire de Paris, Ph.D

Kuchynka, P., Laskar, J., Fienga, A., Manche, H., \& Somenzi, L. 2008, Journees Astrometry, Geodynamics and Astronomical Reference Systems, ed. M. Soffel, \& N. Capitaine (Dresden)

Kuchynka, P., Laskar, J., Fienga, A., \& Manche, H. 2010, A\&A, 514, A96

Laskar, J., \& Robutel, P. 1995, Cel. Mech. Dyn. Astron., 62, 193

Marchis, F., Descamps, P., Berthier, J., et al. 2008a, Icarus, 195, 295

Marchis, F., Descamps, P., Baek, M., et al. 2008b, Icarus, 196, 97

Mouret, S., Hestroffer, D., \& Mignard. F. 2007, A\&A, 472, 1017

Mouret, S., Simon, J. L., Mignard, F., \& Hestroffer, D. 2009, A\&A, 508, 479
Murray, C. D., \& Dermott, S. F. 1999, Solar System Dynamics (Cambridge University Press)

Pitjeva, E. V., \& Standish, E. M. 2009, Cel. Mech. Dyn. Astron., 103, 365

Simon, J. L. 1987, A\&A, 175, 303

Standish, E. M. 1998, IOM, 312.F, 98

Standish, E. M. 2004, A\&A, 417, 1165

Standish, E. M., \& Fienga, A. 2002, A\&A, 384, 322

Standish, E. M., \& Hellings, R. W. 1989, Icarus, 80, 326

Tedesco, E. F., Cellino, A., \& Zappala, V. 2005, AJ, 129, 2869

Williams, J. G. 1984, Icarus, 57, 1

Williams, J. G. 1989, Asteroid family identifications and proper elements, ed.

R. P. Binzel, T. Gehrels, M. Matthews (Asteroids II, Univ. of Arizona Press), 1034

Yeomans, D. K., Barriot, J. P., Dunham, D. W., et al. 1997, Science, 278, 2106 


\section{Appendix A: Effects on the Mars orbital motion}

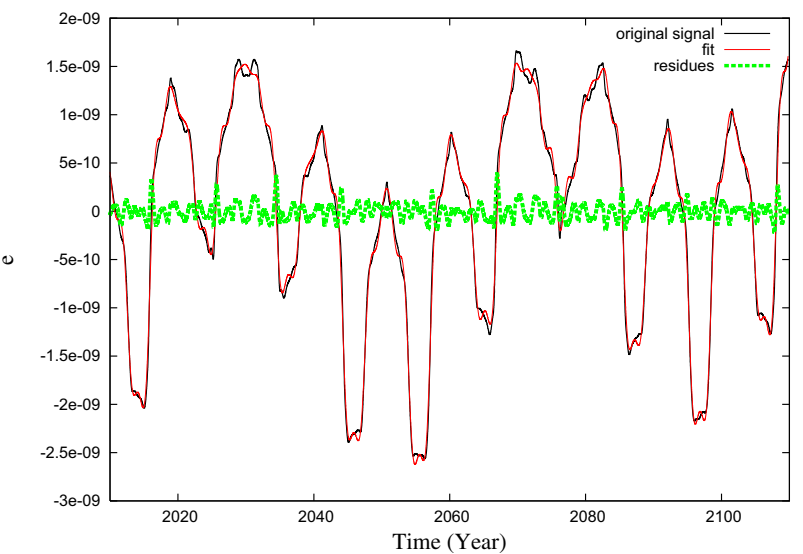

Fig. A.1. Effects of Ceres on $e_{\text {Mars }}$ for a $100 \mathrm{y}$ time interval from JJ 2009.81; raw signal (in black), fitting curve (in red) and residuals (in green).

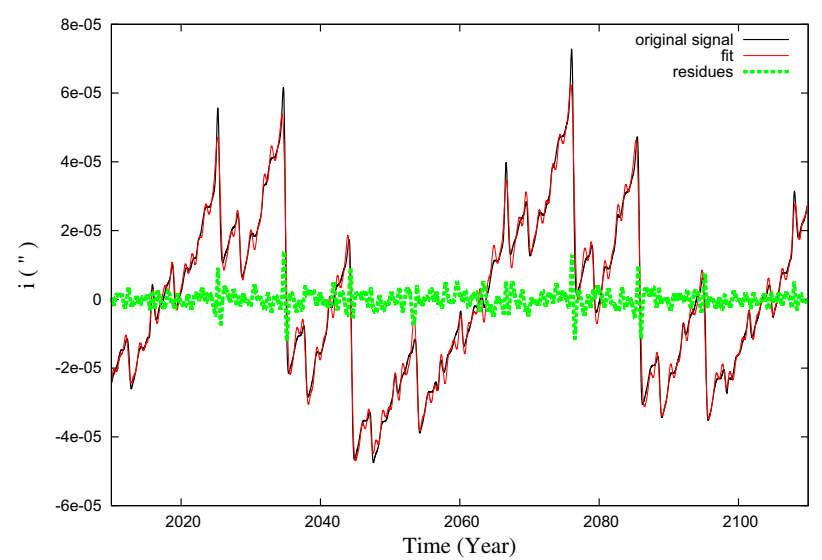

Fig. A.2. Effects of Ceres on $i_{\text {Mars }}$ for a 100 y time interval from JJ 2009.81; raw signal (in black), fitting curve (in red) and residuals (in green).

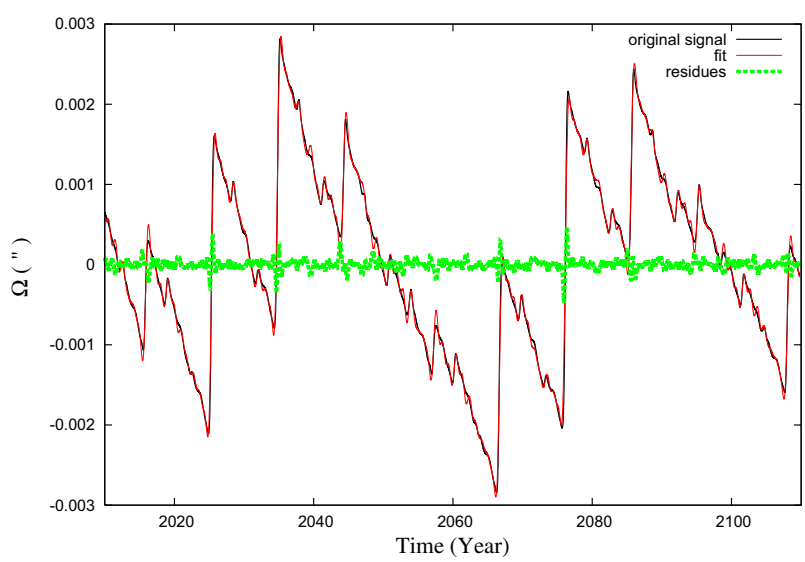

Fig. A.3. Effects of Ceres on $\Omega_{\text {Mars }}$ for a $100 \mathrm{y}$ time interval from JJ 2009.81; raw signal (in black), fitting curve (in red) and residuals (in green).

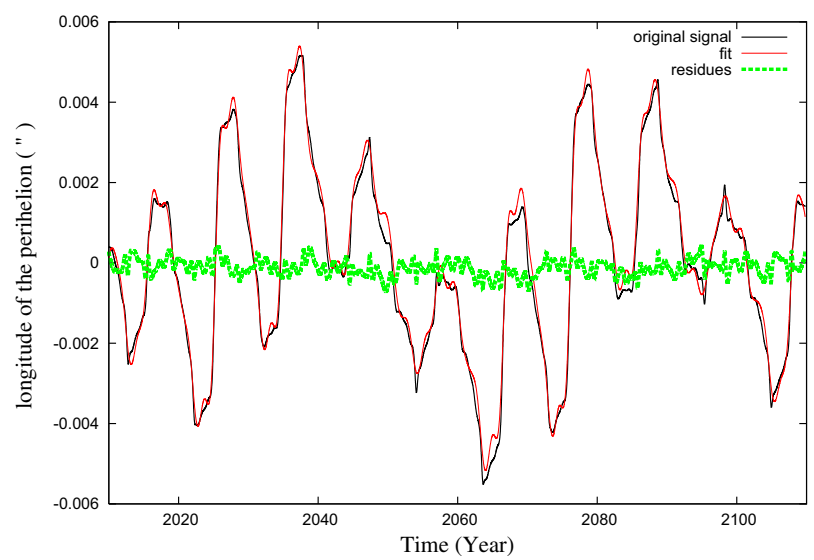

Fig. A.4. Effects of Ceres on $\tilde{\omega}_{\text {Mars }}$ for a 100 y time interval from JJ 2009.81; raw signal (in black), fitting curve (in red) and residuals (in green). 
S. Aljbaae and J. Souchay: Effects of the large asteroids on terrestrial planets

Table A.1. Coefficients of Fourier and Poisson series for the effects of Ceres on $e_{\text {Mars }}$.

\begin{tabular}{|c|c|c|c|c|c|c|c|c|c|}
\hline $\begin{array}{l}\text { period } \\
\text { (Day) }\end{array}$ & $\begin{array}{l}\text { period } \\
\text { (Year) }\end{array}$ & $\begin{array}{r}\text { SIN } \\
\times 10^{-10}\end{array}$ & $\begin{array}{r}\mathrm{COS} \\
\times 10^{-10}\end{array}$ & $\times 10^{-10}$ & $\begin{array}{r}T \text { SIN } \\
\times 10^{-14}\end{array}$ & $\begin{array}{l}T \mathrm{COS} \\
\times 10^{-14}\end{array}$ & $\times 10^{-14}$ & $\begin{array}{r}\text { Amplitud } \\
\times 10^{-8}\end{array}$ & Asteroid \\
\hline 16800.43 & 46.00 & 71.042 & -57.060 & 91.120 & -336.820 & 219.769 & 310.801 & 0.145 & 1 Ceres \\
\hline 4862.41 & 13.31 & 0.650 & 4.085 & 4.137 & 1.708 & -18.545 & 26.227 & 0.064 & 1_Ceres \\
\hline 3752.63 & 10.27 & -5.746 & -12.352 & 13.623 & -14.963 & 26.378 & 37.305 & 0.127 & 1_Ceres \\
\hline 3046.97 & 8.34 & 2.753 & -1.422 & 3.099 & 8.535 & 4.919 & 6.957 & 0.046 & 1_Ceres \\
\hline 1875.99 & 5.14 & -4.305 & -4.983 & 6.585 & 11.563 & 32.195 & 45.530 & 0.028 & 1_Ceres \\
\hline 1682.02 & 4.61 & -4.362 & -1.963 & 4.783 & 26.924 & 7.169 & 10.138 & 0.013 & 1_Ceres \\
\hline 1250.69 & 3.42 & -1.101 & 7.132 & 7.217 & 6.247 & -31.438 & 44.460 & 0.009 & 1_Ceres \\
\hline 1083.67 & 2.97 & 1.155 & -0.487 & 1.254 & -7.228 & 0.406 & 0.574 & 0.007 & 1_Ceres \\
\hline 886.91 & 2.43 & -3.654 & 0.482 & 3.686 & 22.982 & 4.080 & 5.769 & 0.018 & 1_Ceres \\
\hline 840.95 & 2.30 & -0.706 & -0.207 & 0.736 & 0.831 & -0.538 & 0.761 & 0.007 & 1_Ceres \\
\hline 717.34 & 1.96 & 1.234 & 1.552 & 1.983 & -2.558 & -8.717 & 12.328 & 0.009 & 1_Ceres \\
\hline 687.04 & 1.88 & 0.063 & -0.479 & 0.483 & -3.217 & 2.391 & 3.381 & 0.006 & 1_Ceres \\
\hline 502.91 & 1.38 & 1.721 & -0.327 & 1.752 & -8.277 & -1.340 & 1.894 & 0.006 & 1_Ceres \\
\hline
\end{tabular}

Notes. Bias: $-0.147732 \times 10^{-5}$; linear: $0.767680 \times 10^{-9} ; T^{2}:-0.246106 \times 10^{-13}$. The next-to-last column indicates the peak-to-peak amplitude of the total mixed component for the $100 \mathrm{y}$ time interval.

Table A.2. Coefficients of Fourier and Poisson series for the effects of Ceres on $i_{\text {Mars }}$.

\begin{tabular}{rr|rrr|rrr|rc}
\hline \hline $\begin{array}{r}\text { Period } \\
\text { (Day) }\end{array}$ & $\begin{array}{r}\text { Period } \\
\text { (Year) }\end{array}$ & $\begin{array}{r}\text { SIN } \\
\times 10^{-5}\end{array}$ & $\begin{array}{r}\text { COS } \\
\times 10^{-5}\end{array}$ & $\times 10^{-5}$ & $\begin{array}{r}T \text { SIN } \\
\times 10^{-9}\end{array}$ & $\begin{array}{r}T \text { COS } \\
\times 10^{-9}\end{array}$ & $\times 10^{-9}$ & $\begin{array}{r}\text { Amplitud } \\
\times 10^{-4}\end{array}$ & Asteroid \\
\hline 16704.15 & 45.73 & -30.404 & -41.976 & 51.830 & 128.455 & 201.120 & 284.427 & 0.354 & $1_{-}$Ceres \\
4871.57 & 13.34 & -3.481 & -0.198 & 3.486 & 16.174 & 2.520 & 3.564 & 0.081 & $1_{-}$Ceres \\
3745.29 & 10.25 & 2.366 & 2.832 & 3.691 & -6.410 & -15.360 & 21.722 & 0.143 & $1_{-}$Ceres \\
3043.72 & 8.33 & 0.387 & 0.930 & 1.007 & -1.532 & -9.749 & 13.788 & 0.111 & $1_{-}$Ceres \\
1878.41 & 5.14 & 0.518 & 0.763 & 0.922 & -1.876 & -5.321 & 7.525 & 0.049 & $1_{-}$Ceres \\
1683.67 & 4.61 & 1.111 & 0.683 & 1.304 & -7.355 & -4.239 & 5.995 & 0.052 & $1_{-}$Ceres \\
1251.11 & 3.43 & -1.761 & 0.037 & 1.762 & 8.127 & 0.333 & 0.471 & 0.026 & $1_{-}$Ceres \\
1161.41 & 3.18 & 1.597 & 0.156 & 1.604 & -5.001 & -0.533 & 0.754 & 0.067 & $1_{-}$Ceres \\
1083.47 & 2.97 & 0.253 & 0.348 & 0.430 & -2.531 & -1.831 & 2.590 & 0.027 & $1_{-}$Ceres \\
887.20 & 2.43 & 0.772 & -1.393 & 1.593 & -2.531 & 7.513 & 10.625 & 0.043 & $1_{-}$Ceres \\
840.94 & 2.30 & -0.626 & 0.521 & 0.814 & 0.989 & -3.728 & 5.273 & 0.050 & $1_{-}$Ceres \\
687.10 & 1.88 & -0.399 & 0.843 & 0.932 & 1.609 & -5.043 & 7.132 & 0.024 & $1_{-}$Ceres \\
580.74 & 1.59 & -0.469 & -0.210 & 0.514 & 0.789 & 0.457 & 0.647 & 0.038 & $1_{-}$Ceres \\
560.56 & 1.53 & -0.124 & -0.154 & 0.198 & 1.263 & 1.183 & 1.673 & 0.017 & $1_{-}$Ceres \\
503.00 & 1.38 & -0.861 & 0.430 & 0.963 & 3.812 & -2.672 & 3.779 & 0.020 & $1_{-}$Ceres \\
487.77 & 1.34 & 0.452 & -0.048 & 0.454 & -1.446 & 1.033 & 1.462 & 0.023 & $1_{-}$Ceres \\
387.16 & 1.06 & -0.661 & -0.235 & 0.701 & 3.708 & 1.657 & 2.344 & 0.017 & $1_{-}$Ceres \\
\hline
\end{tabular}

Notes. Bias: $0.258949 \times 10^{-1}$; linear: $-0.251401 \times 10^{-4} ; T^{2}: 0.600592 \times 10^{-8}$. The next-to-last column indicates the peak-to-peak amplitude of the total mixed component for the $100 \mathrm{y}$ time interval. 
Table A.3. Coefficients of Fourier and Poisson series for the effects of Ceres on $\Omega_{\text {Mars. }}$.

\begin{tabular}{|c|c|c|c|c|c|c|c|c|c|}
\hline $\begin{array}{r}\text { Period } \\
\text { (Day) }\end{array}$ & $\begin{array}{l}\text { Period } \\
\text { (Year) }\end{array}$ & $\begin{array}{c}\text { SIN } \\
\times 10^{-4}\end{array}$ & $\begin{array}{c}\mathrm{COS} \\
\times 10^{-4}\end{array}$ & $\times 10^{-4}$ & $\begin{array}{l}T \text { SIN } \\
\times 10^{-7}\end{array}$ & $\begin{array}{l}T \mathrm{COS} \\
\times 10^{-7}\end{array}$ & $\times 10^{-7}$ & $\begin{array}{c}\text { Amplitud } \\
\times 10^{-2}\end{array}$ & Asteroid \\
\hline 17237.30 & 47.19 & -254.868 & 163.129 & 302.603 & 120.532 & -84.520 & 119.529 & 0.126 & 1_Ceres \\
\hline 10945.54 & 29.97 & 3.333 & 13.201 & 13.616 & -1.550 & -6.445 & 9.114 & 0.116 & 1_Ceres \\
\hline 7586.87 & 20.77 & -3.312 & -4.891 & 5.907 & 1.250 & 2.352 & 3.326 & 0.054 & 1_Ceres \\
\hline 4921.78 & 13.48 & 7.651 & -0.338 & 7.658 & -3.232 & 0.853 & 1.207 & 0.036 & 1_Ceres \\
\hline 3754.45 & 10.28 & 1.482 & -1.680 & 2.241 & 2.192 & 0.170 & 0.241 & 0.078 & 1_Ceres \\
\hline 3045.26 & 8.34 & 0.149 & 5.993 & 5.995 & -2.205 & -4.246 & 6.005 & 0.056 & 1_Ceres \\
\hline 1877.72 & 5.14 & -6.977 & 1.328 & 7.102 & 4.562 & -0.518 & 0.733 & 0.030 & 1_Ceres \\
\hline 1681.32 & 4.60 & -0.203 & -3.210 & 3.216 & -1.143 & 1.428 & 2.019 & 0.029 & 1_Ceres \\
\hline 1521.01 & 4.16 & 3.786 & -0.861 & 3.882 & -1.957 & 0.150 & 0.212 & 0.006 & 1_Ceres \\
\hline 1252.35 & 3.43 & -0.665 & 0.300 & 0.729 & 0.284 & 0.253 & 0.357 & 0.014 & 1_Ceres \\
\hline 1161.48 & 3.18 & -2.464 & 1.778 & 3.038 & 0.017 & -1.536 & 2.172 & 0.031 & 1_Ceres \\
\hline 1083.21 & 2.97 & -1.423 & -0.137 & 1.429 & 1.120 & 0.322 & 0.456 & 0.010 & 1_Ceres \\
\hline 887.02 & 2.43 & 5.332 & -2.557 & 5.913 & -3.223 & 1.151 & 1.628 & 0.018 & 1_Ceres \\
\hline 840.68 & 2.30 & -0.150 & -0.303 & 0.338 & 0.904 & 0.412 & 0.582 & 0.019 & 1_Ceres \\
\hline 717.62 & 1.96 & 3.271 & 1.048 & 3.435 & -1.827 & -0.739 & 1.045 & 0.009 & 1_Ceres \\
\hline 686.93 & 1.88 & 0.479 & -5.096 & 5.119 & 0.187 & 2.734 & 3.866 & 0.012 & 1_Ceres \\
\hline 580.74 & 1.59 & -3.886 & -1.628 & 4.214 & 2.118 & 1.406 & 1.989 & 0.016 & 1_Ceres \\
\hline 560.52 & 1.53 & 0.764 & 1.457 & 1.645 & -0.390 & -0.971 & 1.374 & 0.006 & 1_Ceres \\
\hline 502.94 & 1.38 & -1.693 & -1.005 & 1.969 & 1.027 & 0.679 & 0.960 & 0.007 & 1_Ceres \\
\hline 487.69 & 1.34 & -2.055 & 1.376 & 2.473 & 0.739 & -0.930 & 1.316 & 0.008 & 1_Ceres \\
\hline 431.64 & 1.18 & 2.216 & 3.012 & 3.739 & -1.231 & -1.633 & 2.309 & 0.006 & 1_Ceres \\
\hline 387.16 & 1.06 & 0.068 & 3.096 & 3.097 & -0.005 & -1.781 & 2.519 & 0.006 & 1_Ceres \\
\hline 343.47 & 0.94 & -1.495 & -3.287 & 3.611 & 0.833 & 1.882 & 2.661 & 0.008 & 1_Ceres \\
\hline
\end{tabular}

Notes. Bias: -0.811114 ; linear: $0.427426 \times 10^{-3} ; T^{2}:-0.121763 \times 10^{-7}$. The next-to-last column indicates the peak-to-peak amplitude of the total mixed component for the $100 \mathrm{y}$ time interval.

Table A.4. Coefficients of Fourier and Poisson series for the effects of Ceres on $\tilde{\omega}_{\text {Mars }}$.

\begin{tabular}{|c|c|c|c|c|c|c|c|c|c|}
\hline $\begin{array}{r}\text { Period } \\
\text { (Day) }\end{array}$ & $\begin{array}{l}\text { Period } \\
\text { (Year) }\end{array}$ & $\begin{array}{r}\text { SIN } \\
\times 10^{-4}\end{array}$ & $\begin{array}{r}\mathrm{COS} \\
\times 10^{-4}\end{array}$ & $\times 10^{-4}$ & $\begin{array}{l}T \text { SIN } \\
\times 10^{-7}\end{array}$ & $\begin{array}{r}\text { COS } \\
\times 10^{-7}\end{array}$ & $\times 10^{-7}$ & $\begin{array}{r}\text { Amplitud } \\
\times 10^{-2}\end{array}$ & Asteroid \\
\hline 17112.22 & 46.85 & -156.276 & 611.164 & 630.828 & 70.223 & -290.043 & 410.183 & 0.311 & 1_Ceres \\
\hline 10842.14 & 29.68 & 276.449 & 3.355 & 276.470 & -134.342 & -2.937 & 4.153 & 0.378 & 1_Ceres \\
\hline 4924.23 & 13.48 & 0.168 & -17.541 & 17.542 & 0.160 & 9.637 & 13.629 & 0.115 & 1_Ceres \\
\hline 3755.58 & 10.28 & 25.200 & -2.573 & 25.331 & -0.378 & 2.019 & 2.855 & 0.273 & 1_Ceres \\
\hline 3046.85 & 8.34 & -7.000 & -5.383 & 8.831 & 2.778 & -2.097 & 2.965 & 0.099 & 1_Ceres \\
\hline 1877.78 & 5.14 & -2.572 & -2.221 & 3.398 & 3.756 & 1.278 & 1.808 & 0.060 & 1_Ceres \\
\hline 1681.96 & 4.60 & -2.301 & 12.463 & 12.674 & 0.668 & -7.302 & 10.327 & 0.031 & 1_Ceres \\
\hline 1251.92 & 3.43 & -5.802 & -7.270 & 9.301 & 3.454 & 3.746 & 5.298 & 0.014 & 1 Ceres \\
\hline 1083.69 & 2.97 & 6.023 & -8.188 & 10.165 & -3.391 & 4.274 & 6.044 & 0.012 & 1_Ceres \\
\hline 887.10 & 2.43 & 6.554 & 1.009 & 6.632 & -4.692 & -1.180 & 1.669 & 0.039 & 1_Ceres \\
\hline 840.86 & 2.30 & 0.293 & 0.606 & 0.673 & -0.137 & 0.308 & 0.435 & 0.012 & 1_Ceres \\
\hline 717.65 & 1.96 & 3.002 & 2.539 & 3.931 & -1.857 & -1.823 & 2.578 & 0.017 & 1_Ceres \\
\hline 687.08 & 1.88 & 4.640 & 3.120 & 5.591 & -2.526 & -1.043 & 1.474 & 0.012 & 1_Ceres \\
\hline 502.96 & 1.38 & 0.513 & -1.741 & 1.815 & 0.007 & 1.204 & 1.703 & 0.010 & 1_Ceres \\
\hline
\end{tabular}

Notes. Bias: $-0.605169 \times 10^{+2}$; linear: $-0.121834 \times 10^{-1} ; T^{2}: 0.156335 \times 10^{-5}$. The next-to-last column indicates the peak-to-peak amplitude of the total mixed component for the $100 \mathrm{y}$ time interval. 
S. Aljbaae and J. Souchay: Effects of the large asteroids on terrestrial planets

Table A.5. Coefficients of Fourier and Poisson series for the effects of Pallas on $a_{\text {Mars }}$.

\begin{tabular}{|c|c|c|c|c|c|c|c|c|c|}
\hline $\begin{array}{r}\text { Period } \\
\text { (Day) }\end{array}$ & $\begin{array}{l}\text { Period } \\
\text { (Year) }\end{array}$ & $\begin{array}{r}\text { SIN } \\
\times 10^{0}\end{array}$ & $\begin{array}{l}\mathrm{COS} \\
\times 10^{0}\end{array}$ & $\times 10^{0}$ & $\begin{array}{l}T \text { SIN } \\
\times 10^{-3}\end{array}$ & $\begin{array}{r}T \mathrm{COS} \\
\times 10^{-3}\end{array}$ & $\times 10^{-3}$ & $\begin{array}{r}\text { Amplitud } \\
\times 10^{1}\end{array}$ & Asteroid \\
\hline 21839.28 & 59.79 & -10.566 & 1.282 & 10.644 & 3.470 & -0.149 & 0.210 & 1.031 & 2_Pallas \\
\hline 17918.54 & 49.06 & -107.297 & 3.679 & 107.360 & 16.781 & -2.048 & 2.896 & 7.353 & 2_ Pallas \\
\hline 9865.09 & 27.01 & -9.001 & 4.336 & 9.991 & 2.672 & -0.949 & 1.342 & 0.446 & 2_Pallas \\
\hline 8955.04 & 24.52 & 12.925 & 19.794 & 23.640 & -3.318 & -3.703 & 5.236 & 1.412 & 2_Pallas \\
\hline 6364.17 & 17.42 & 5.432 & 9.561 & 10.996 & -0.971 & -1.935 & 2.736 & 0.621 & 2_Pallas \\
\hline 5974.81 & 16.36 & 4.910 & -2.340 & 5.439 & -0.825 & 1.045 & 1.478 & 0.290 & 2_Pallas \\
\hline 4695.27 & 12.85 & 13.748 & -17.279 & 22.081 & -2.510 & 2.891 & 4.088 & 1.480 & 2_Pallas \\
\hline 3720.02 & 10.18 & -3.842 & -4.707 & 6.075 & -0.432 & 0.013 & 0.018 & 0.680 & 2_Pallas \\
\hline 3080.06 & 8.43 & -2.749 & -5.035 & 5.736 & 0.396 & -0.555 & 0.785 & 0.699 & 2_Pallas \\
\hline 2628.38 & 7.20 & -8.639 & -1.328 & 8.740 & 1.655 & 0.137 & 0.194 & 0.560 & 2_Pallas \\
\hline 2075.66 & 5.68 & 1.660 & 7.042 & 7.236 & -0.231 & -1.369 & 1.937 & 0.488 & 2_Pallas \\
\hline 1860.14 & 5.09 & 15.833 & -9.731 & 18.584 & -2.247 & 1.721 & 2.434 & 1.301 & 2_Pallas \\
\hline 1540.23 & 4.22 & 3.956 & -4.351 & 5.880 & -0.578 & 0.830 & 1.173 & 0.385 & 2_Pallas \\
\hline 1240.07 & 3.40 & 0.060 & 9.006 & 9.006 & -0.144 & -1.609 & 2.275 & 0.579 & 2_Pallas \\
\hline 930.06 & 2.55 & -3.330 & -2.179 & 3.980 & 0.558 & 0.278 & 0.393 & 0.298 & 2_Pallas \\
\hline 884.18 & 2.42 & -8.246 & 9.304 & 12.432 & 0.721 & -1.233 & 1.744 & 0.966 & 2_Pallas \\
\hline 714.39 & 1.96 & -2.652 & -6.204 & 6.747 & 0.530 & 0.901 & 1.274 & 0.464 & 2_Pallas \\
\hline 579.91 & 1.59 & 1.465 & -5.380 & 5.576 & 0.679 & -0.289 & 0.408 & 0.718 & $2_{-}^{-}$Pallas \\
\hline 501.71 & 1.37 & 3.219 & 3.088 & 4.461 & -0.590 & -0.005 & 0.008 & 0.368 & 2_Pallas \\
\hline 442.08 & 1.21 & -2.850 & 0.973 & 3.011 & 0.416 & -0.174 & 0.246 & 0.215 & 2_Pallas \\
\hline 408.23 & 1.12 & -10.042 & 36.276 & 37.640 & 4.874 & -18.183 & 25.715 & 1.902 & 2_Pallas \\
\hline 386.59 & 1.06 & -0.348 & 0.504 & 0.613 & -0.644 & -0.204 & 0.288 & 0.230 & 2_Pallas \\
\hline 272.16 & 0.75 & -15.594 & -2.638 & 15.815 & 7.718 & 1.194 & 1.688 & 0.770 & 2_Pallas \\
\hline
\end{tabular}

Notes. Bias: $0.398536 \times 10^{+4}$; linear: $-0.326098 \times 10^{+1} ; T^{2}: 0.651096 \times 10^{-3}$. The next-to-last column indicates the peak-to-peak amplitude of the total mixed component for the $1000 \mathrm{y}$ time interval considered.

Table A.6. Coefficients of Fourier and Poisson series for the effects of Vesta on $a_{\text {mars }}$.

\begin{tabular}{|c|c|c|c|c|c|c|c|c|c|}
\hline $\begin{array}{r}\text { Period } \\
\text { (Day) } \\
\end{array}$ & $\begin{array}{r}\text { Period } \\
\text { (Year) }\end{array}$ & $\begin{array}{r}\text { SIN } \\
\times 10^{0} \\
\end{array}$ & $\begin{array}{r}\mathrm{COS} \\
\times 10^{0} \\
\end{array}$ & $\times 10^{0}$ & $\begin{array}{r}T \text { SIN } \\
\times 10^{-3} \\
\end{array}$ & $\begin{array}{r}T \mathrm{COS} \\
\times 10^{-3} \\
\end{array}$ & $\times 10^{-3}$ & $\begin{array}{r}\text { Amplitud } \\
\times 10^{2} \\
\end{array}$ & Asteroid \\
\hline 18867.98 & 51.66 & 83.834 & -107.509 & 136.331 & -3.213 & 4.449 & 6.291 & 1.267 & 4_Vesta \\
\hline 9443.39 & 25.85 & 17.064 & -41.235 & 44.626 & -0.487 & 2.848 & 4.027 & 0.389 & 4_ Vesta \\
\hline 6296.23 & 17.24 & 3.447 & -4.872 & 5.968 & 1.009 & -0.857 & 1.211 & 0.100 & 4_Vesta \\
\hline 1679.56 & 4.60 & 0.997 & 12.655 & 12.695 & 0.599 & -1.360 & 1.923 & 0.105 & 4_ Vesta \\
\hline 1542.42 & 4.22 & 0.669 & 28.454 & 28.462 & -0.482 & -1.519 & 2.149 & 0.255 & 4_Vesta \\
\hline 1425.93 & 3.90 & -1.302 & 10.131 & 10.215 & -0.384 & 0.443 & 0.627 & 0.115 & 4_Vesta \\
\hline 740.95 & 2.03 & -0.607 & 13.687 & 13.700 & -0.711 & -0.238 & 0.337 & 0.140 & 4_ Vesta \\
\hline 712.97 & 1.95 & -8.158 & 30.122 & 31.208 & -1.160 & -0.688 & 0.972 & 0.307 & 4_Vesta \\
\hline 487.59 & 1.33 & -1.036 & 10.484 & 10.535 & -1.058 & -1.360 & 1.924 & 0.083 & 4_ Vesta \\
\hline 475.32 & 1.30 & -5.351 & 15.041 & 15.964 & -1.000 & -0.548 & 0.775 & 0.158 & 4_Vesta \\
\hline 408.23 & 1.12 & 30.965 & -107.157 & 111.541 & -14.906 & 53.474 & 75.624 & 0.555 & 4_Vesta \\
\hline 356.49 & 0.98 & -2.836 & 7.467 & 7.988 & -1.067 & -0.451 & 0.638 & 0.086 & 4_Vesta \\
\hline 272.16 & 0.75 & 40.158 & 30.629 & 50.506 & -19.865 & -14.742 & 20.848 & 0.240 & 4_Vesta \\
\hline AMPLITUDE & \multicolumn{3}{|c|}{ Before $=545.913598$} & \multicolumn{4}{|c|}{ After $=146.660553$} & & \\
\hline
\end{tabular}

Notes. Bias: $0.152498 \times 10^{+3}$; linear: $-0.209840 \times 10^{-1} ; T^{2}: 0.445801 \times 10^{-5}$. The next-to-last column indicates the peak-to-peak amplitude of the total mixed component for the $1000 \mathrm{y}$ time interval considered. 
Appendix B: individual and combined asteroidal effects

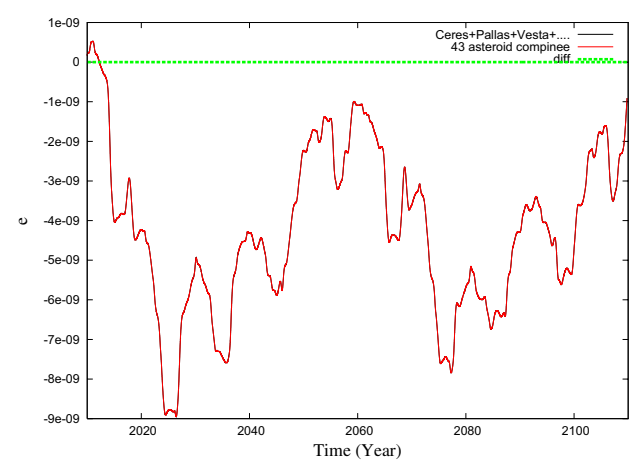

Fig. B.1. Combined effects of the 43 asteroids on $e_{\text {Mars }}$. The curve in green represents the difference between two ways of computation: adding individual perturbations, or making a combined integration.

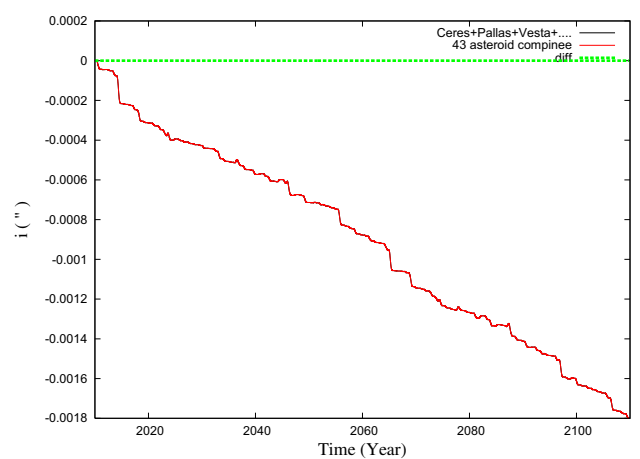

Fig. B.2. Zoom of the green curve of Fig. B.1, showing the difference between two ways of computation.

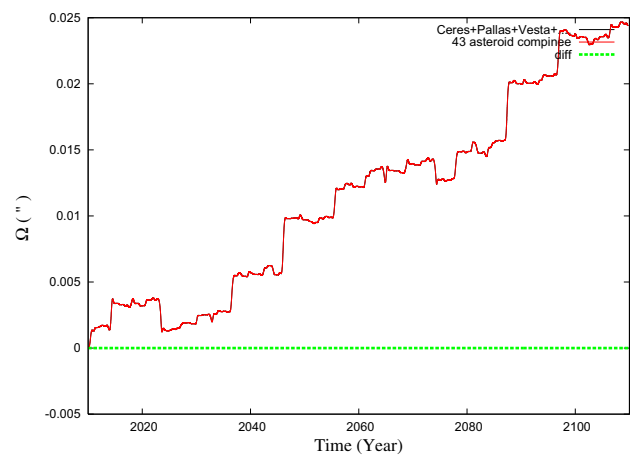

Fig. B.3. Combined effects of the 43 asteroids on $i_{\text {Mars }}$. The curve in green represents the difference between two ways of computation: adding individual perturbations, or making a combined integration.

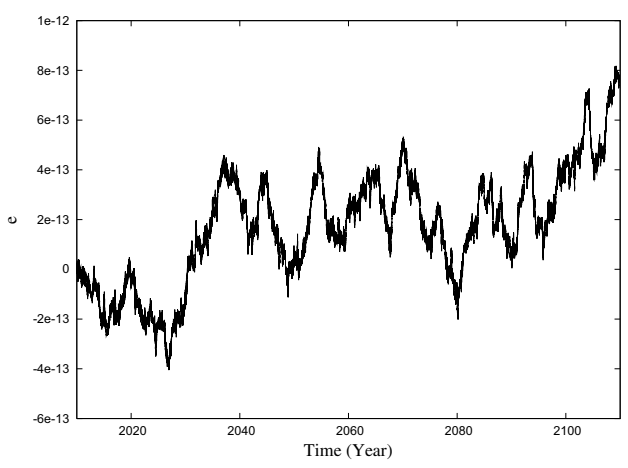

Fig. B.4. Zoom of the green curve of Fig. B.3, showing the difference between two ways of computation.

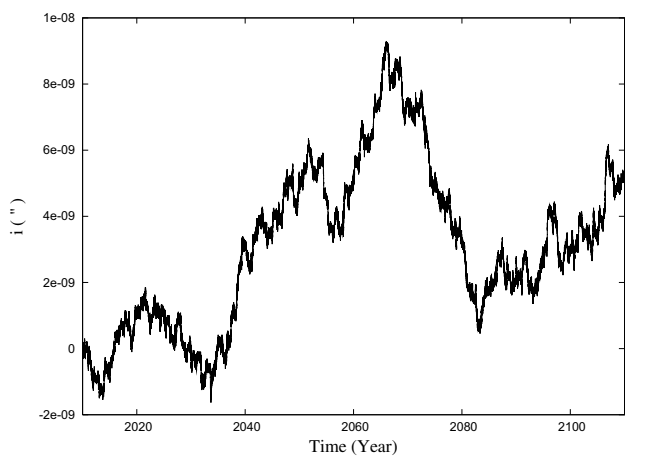

Fig. B.5. Combined effects of the 43 asteroids on $\Omega_{\text {Mars }}$. The curve in green represents the difference between two ways of computation: adding individual perturbations, or making a combined integration.

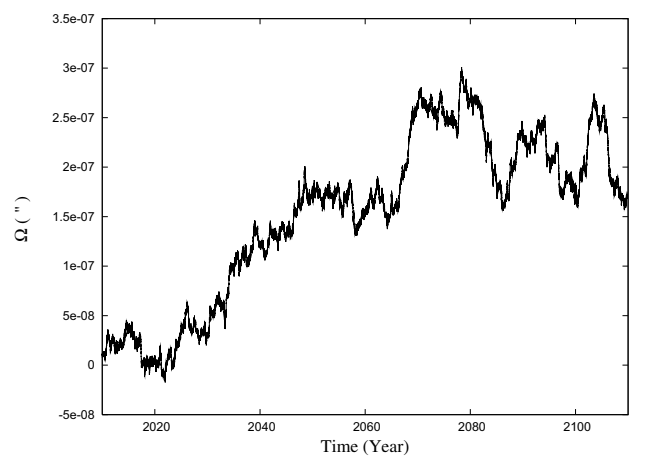

Fig. B.6. Zoom of the green curve of Fig. B.5, showing the difference between two ways of computation. 
S. Aljbaae and J. Souchay: Effects of the large asteroids on terrestrial planets

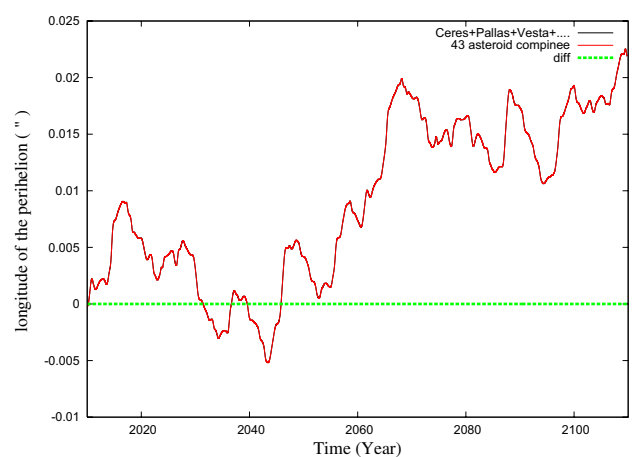

Fig. B.7. Combined effects of the 43 asteroids on $\tilde{\omega}_{\text {Mars }}$. The curve in green represents the difference between two ways of computation: adding individual perturbations, or making a combined integration.

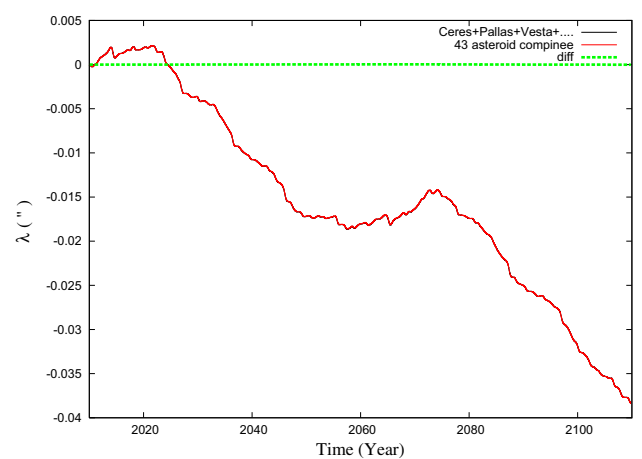

Fig. B.8. Zoom of the green curve of Fig. B.7, showing the difference between two ways of computation.

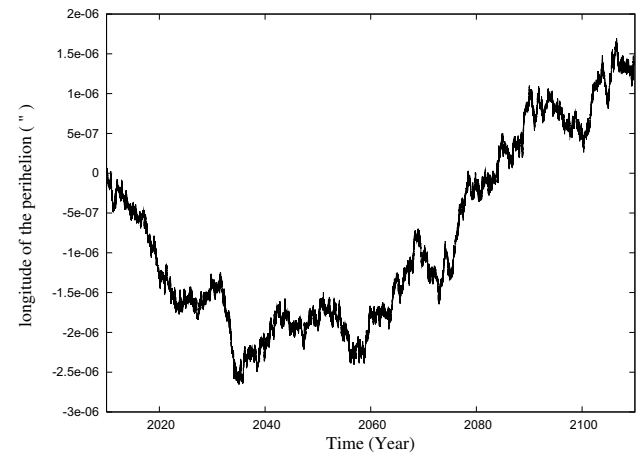

Fig. B.9. Combined effects of the 43 asteroids on $\lambda_{\text {Mars }}$. The curve in green represents the difference between two ways of computation: adding individual perturbations, or making a combined integration.

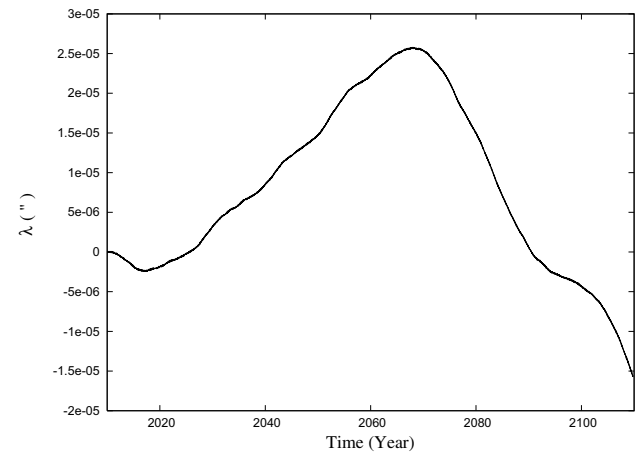

Fig. B.10. Zoom of the green curve of Fig. B.9, showing the difference between two ways of computation.
Appendix C: Use of ASTEP for ephemerides study

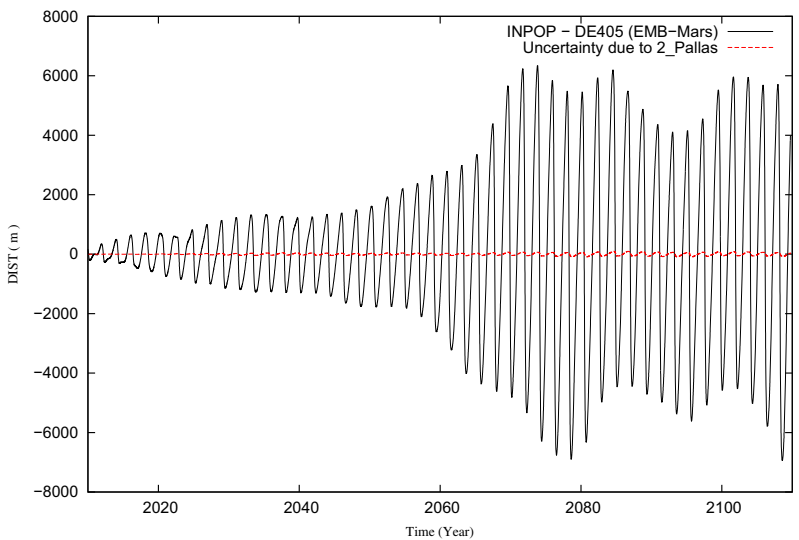

Fig. C.1. Uncertainty of the EMB-to-Mars distance due to the lack of accuracy in Pallas' mass (red curve) and difference in the EMB-to-Mars distance between DE405 and INPOP08 (black curve).

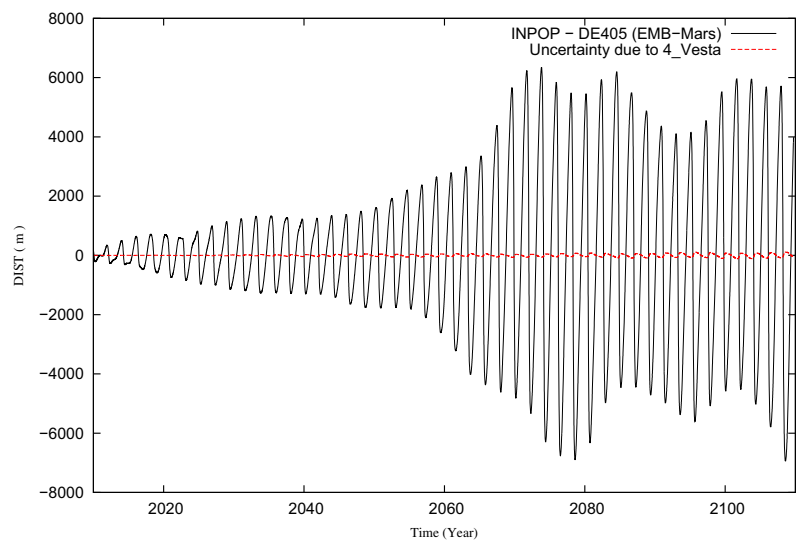

Fig. C.2. Uncertainty of the EMB-to-Mars distance due to the lack of accuracy in Vesta's mass (red curve) and difference in the EMB-to-Mars distance between DE405 and INPOP08 (black curve). 